\title{
Zur Diagnose, Prognose und Therapie der perforirenden, inficirten Augapfelverletzungen.
}

\author{
Von \\ Prof. Otto Schirmer \\ in Greifswald.
}

Durchsucht man die statistischen Arbeiten der neueren und älteren Literatur, um Auskunft zu erhalten über die Prognose der perforirenden Bulbusverletzungen, so stösst man überall auf das Princip [z. B. bei Hillemannsis), Ohlemann ${ }^{2}$ ), Römer ${ }^{3}$ ), Silex $\left.{ }^{4}\right)$ ], die Verletzungen nach ihrer anatomischen Lage einzutheilen, als ob hierdurch wesentlich die Prognose bedingt würde. $O b$ die $W$ unde inficirt war oder nicht, ist aus den Arbeiten überhaupt nicht zu ersehen, obgleich doch dies für Prognose und Therapie der wichtigste Punkt ist, obgleich es sogar, wenn ich von den völligen Zerschmetterungen des Bulbus und dem starken Glaskörperverlust absehe, für die Erhaltung des Bulbus allein wichtig ist. Nur für die aseptischen Wunden ist ihre Lage, Form, Ausdehnung etc. von Bedeutung; aber auch nur insofern, als davon abhängt, wie viel Sehvermögen wir dem Patienten erhalten können; der Augapfel muss bei richtiger Behandlung immer gerettet werden, falls keine der beiden ebengenannten Eventualitäten zutrifft und falls er keinen Fremdkörper beherbergt.

Viel ungünstiger lautet die Prognose bei den inficirten perforirenden. Wunden, aber wir haben doch absolut keinen Grund zu solch pessimistischer Vorhersage, wie sie sich in fast allen neueren Lehrbüchern und besonders präcis ausgedrückt in „Die Verletzungen des

1) Ueber Verletzungen des Auges. Arch. f. Augenheilk. XXX. S. 29. 1895.

2) Die perforirenden Augenverletzungen mit Rücksicht auf die sympathische Ophthalm. ibid. XXIT. S. 94. 1891. ${ }^{3}$ ) Die conservative Behandlung der perforirenden Bulbusverletzungen. Zeitschr. f. prakt. Aerzte, 1899.

4) Ueber perforirende Wunden der Cornea und sklera. Berl. klin. Wochenschrift. 1888. S. 396.

จ. Graefe's Archiv für Ophthalmologie. LIII. 1. 
0. Schirmer.

Auges" von Praun (Wiesbaden, 1899) tinclet. Dieser Autor sagt ron den eitrigen Infectionen S. 62: "Die Prognose ist sehr ungünstig, weil das Auge unter grossen. Schmerzen in der Regel rettungslos verloren geht," und von der fibrinösen Iridocyclitis: „Die Prognose ist durchaus schlecht. Ist der Process einmal im Gange, so darf man froh sein, ein nicht zu kleines, nicht mehr schmerzhaftes Auge zu erhalten; die Erblindung ist immer unabwendbar."

Vereinzelte Publicationen aus den letzten Jahren haben gezeigt, dass auch in diesen Fällen die Prognose nicht absolut schlecht ist; so z. B. berichten Hirschberg ${ }^{1}$ ), Deutschmann ${ }^{2}$ ), v. Millingen ${ }^{3}$ ), Haab $^{4}$ ), Darier ${ }^{5}$ ), Horitz ${ }^{6}$ ) u. A. ron eitrigen Infectionen, bei welchen es ihnen gelang, die Bulbi und einen Theil des Sehvermögens zu erhalten, und ähnliche Beobachtungen wird wohl Jeder hin und wieder zu verzeichnen haben. In Folgendem möchte ich über eine, allerdings nicht neue Behandlungsmethode berichten, deren consequente und energische Durchführung mir Resultate gegeben hat, die mir den bisher publicirten wesentlich tuberlegen zu sein scheinen und welche die Vorhersage auch bei den inficirten Verletzungen, falls sie mir frisch in die Behandlung des Arztes kommen, als durchaus nicht so sehr schlecht erscheinen lassen. Vor Allem das Studium der Behandlungsweisen bei sympathischer Entziindung, bei welcher alle Autoren das Quecksilber als das souveräne Mittel anerkennen, brach te wich auf die Idee, es systematisch auch bei den infectiösen Entziindungen nach Traumen anzuwenden, die ich ja ihrem Wesen nach mit der sympathischen Entzündung für gleichwerthig halte. Natürlich wurden dabei die anderen uns zu Gebote stehenden Mittel nicht vernachlässigt. Ich verfüge jetzt über 133 nach annähernd gleichen Giundsätzen behandelte, perforirende Verletzungen, von welchen fast die Hälfte inficirt in meine Behandlung trat. Ehe ich jedoch näher auf dieselben eingehe, ist es nöthig, in wenigen Worten aus einander zu setzen, woran wir die eingetretene Infection erkennen, da die Ansichten über diesen Punkt durchaus woch nicht geklärt sind.

Die Anwesenheit pathogener Mikroorganismen in einem Gewe be erkennt man klinisch an Veränderungen des betreffenden Gewebes, die eine Abwehr, womöglich eine Elimination oder Abtödtung der Eindringlinge zum Ziel haben und unter dem Namen der bakteriellen

1) Centralbl. f. Augenheilk. 1889, S. $267 . \quad$ ) Beiträge zur Augenheilk, 1895. Bd. II. S. $461 . \quad$ ') Centralbi. f. Augenheilk. 1899, S. 161. ") Utrechter internationaler Congress. 1899, S. $425 . \quad$ 5) Heidelberger Congress. 1893 , S. $99 . \quad$ G) Ḱlin. Monatsbl. f. Augenheilk. 1901, Jan. Febr. 
Zur Diagnose, Prognose u. Therapie d, perforir., inficirten Augapfelverletzungen. 3

Entzïndung zusammengefasst werden. Pathogene Mikrobien in Bulbusinneren versetzen fast stets in erster Linie die Uvea in Entzündung, und zwar je nachdem ihre Eingangspforte weiter nach vorn oder nach hinten gelegen ist, die Iris, den Ciliarkörper oder die Aderhaut. Sie haben aber die Neigung, von dem zuerst ergriffenen Abschnitt aus anch in die beiden anderen Theile der" Uvea einzuwandern. Klinisch werden wir deshalb in erster Linie immer die Tris verändert finden, da wir in dieser schon viel geringere Grade ron Entzündung mit Sicherheit diagnosticiren können, wie an Ciliarkörper und Aderhaut. Doch kommen auch Fälle vor, wo z. B. ein Glaskörperabscess erkannt werden kann, während die Iris nichts weiter als Hyperämie zeigt.

Die Schwierigkeit, eine stattgehabte Infection $\mathrm{zu}$ diagnosticiren, beruht nu darin, dass die gleichen Symptome, die einer beginnenden bakteriellen Entzündung zukommen, wie pericomeale Injection, Hyperämie und Verfärbung der Iris, schlechte Pupillarreaction, selbst Bildung hinterer Synechien, auch ohne Bakterien durch die mechanische Wirkung der Verletzung, durch Gewebszerreissungen, Blutergüsse und vor Allem durch quellende Linsenmassen erzeugt werden können. Die mechanische Reizung der Nerven und in noch höherem Masse die chemische Reizung der Gewebe durch Lösung z. B. von Linsenmassen im Kammerwasser - am schönsten nach Myopiediscisionen zu beobachten - üben eine analoge Wirkung aus, wie die Stoffwechselproducte der Mikrobien. Schreitet die bakterielle Entzündung fort, dann ist freilich die Fntscheidung leicht zu treffen, denn jene aseptischen Reactionserscheinungen erreichen niemals hohe Grade. Werden aber die Gewebe bald der eingedrungenen Bakterien Herr, so braucht die Entzündung niemals über die Anfangsstadien hinauszugehen, und man kann in solchen Fällen sehr wohl zweifelhaft bleiben, ob die rorhandenen Reactionserscheinungen schon auf eine leichte Infection hindeuteten, oder sich noch aus den mechanischen Folgen der Verletzung erklären liessen. Das aber lässt sich als sicher hinstellen: länger dauernde und schwerere Uvealentzündungen, mögen sie acut oder chronisch, eitríg oder fibrinös oder serös sein, kommen ohne die Mitwirkung von Bakterien niemals zu Stande. Mechanische Veränderungen, wie Iris-oder Kapseleinklemmungen, Narben im Ciliarkörper oder dergl., vermögen dieselben nicht zu erzeugen. Auf die Gründe, die hiergegen sprechen, näher einzugehen, würde zu weit führen. Wer noch an diese Möglichkeit denkt, den verweise ich auf den 32. Abschnitt in Leber's Werk: Ueber die 
0. Schirmer.

Entstehung der Entzïndung (Leipzig 1891), oder aut meine Arbeiten über die sympathische Entzündung ${ }^{1}$ ), wo diese Frage ausführlich behandelt ist.

Nach der Art der Exsudation unterscheiden wir drei Hauptformen der Uvealentzindung: die eitrige, die fibrinöse oder plastische und die sog. seröse, kenntlich an den Descemet'schen Beschlägen. Von der ersten wird allgemein zugegeben, dass sie - von der Kupfereiterung abgesehen - stets durch Infection entsteht; uber die Entstehung der fibrinösen Eatzündung sind die Ansichten noch getheilt, und das Vorkommen rein seröser Formen habe ich nirgends erwähnt gefunden; es gehört jedenfalls zu den Seltenheiten.

Whe ich jedoch auf diese dref Formen traumatisch-infectiöser Uveitiden näher eingehe, noch einige Worte über meine Resultate bei den perforirenden aseptischen Wunden.

Unter 133 perforirenden Verletzungen, die innerhalb der letzten sechs Jahre frisch - d. h. innerhalb der ersten zehn Tage - in meine Behandlung traten, waren 71 aseptisch. Die perforirende Wunde hatte ihren Sitz $42 \mathrm{Mal}$ in der Hornhant, $19 \mathrm{Mal}$ in der Lederhaut und $10 \mathrm{Mal}$ in Hornhaut und Lederhaut; 13 von diesen Augen beherbergten ausserdem einen Fremdkörper in ihrem Inneren. Die Resultate sind folgende:

\begin{tabular}{|c|c|c|c|c|c|c|c|c|}
\hline & $\begin{array}{l}\text { Primär } \\
\text { on ueleirt }\end{array}$ & $\mid \begin{array}{c}\text { Sectndar } \\
\text { entoleirt } \\
\text { oder } \\
\text { resevirt }\end{array}$ & $\begin{array}{l}\text { Roizloser } \\
\text { aber } \\
\text { blinder } \\
\text { Bulbus }\end{array}$ & $\begin{array}{l}s .= \\
\text { Finger- } \\
\text { zalthien } \\
-<x^{1} \text { tho }\end{array}$ & $\begin{array}{l}S .=1 / 10 \\
-<5_{10}^{5}\end{array}$ & $\begin{array}{c}S= \\
\delta_{/ 10}=1\end{array}$ & $\begin{array}{l}\text { S branchl- } \\
\text { bar, nicht } \\
\text { bestimn- } \\
\text { bar } \\
\text { (Kinder) }\end{array}$ & Sa. \\
\hline ( & - & --1 & -1 & - & & & & $\approx=$ \\
\hline \multirow{3}{*}{$\begin{array}{l}\text { Cornealwunden } \\
\text { Skleralwunden } \\
\text { Comeoskleral- } \\
\text { wminden }\end{array}$} & 2 & 1 & - & 9 & 10 & 13 & 7 & 42 \\
\hline & 2 & 1 & 3 & 3 & 3 & 5 & 2 & 19 \\
\hline & 1 & 1 & 1 & 1 & 3 & 3 & - & 10 \\
\hline $\mathrm{Sa}$ & 5 & 3 & 4 & 13 & 16 & 21 & 9 & 71 \\
\hline in $\%$ & 7 & 4,2 & 5,6 & 18, & 22,6 & 29,6 & 12,7 & \\
\hline
\end{tabular}

Die fünf primären Enucleationen betreffen völlig zerschmetterte Augen oder Bulbi mit übergrossen IVunden, aus welchen der grösste Theil des Glaskörpers abgeflossen war. Bei den secundär operirten wurde einmal wegen einex aseptischen progressiven Kupfereiterung euucleirt, wo es mir trotz mehrfacher Versuche nicht gelungen war;

1) v. Graefe's Arch. f. Ophthalm. Bd. XXXVIII. 4, 1892, S. 121 ff, s. 126 ff. whd Handbuch Graefe-Saemiseh, II. Auf., Bd. VI, Cap. VIII. 1900, S. 48 fi, S. 58 ffi. etc. 
Zur Diagnose, Prognase u. Therapie d. perforir., inticirten Augapfelverletzungen. j)

den Splitter aus dem Glaskörper zu extrahiren. Die beiden anderen Male resecirte ich in Folge starken Glaskörperverlustes phthisisch gewordene Augen, bei welchen sich dauerd leichte Injection hielt und etwas Schmerzhaftigkeit einstellte ${ }^{1}$ ). Im Uebrigen habe ich den Zahlen nur noch hinzuzufügen, dass in einer Anzahl von Fällen durch Nachoperation oder spontine Aufhellung von Trübungen noch wesentliche Besserung zu erwarten ist.

Ich wende mich nunmehr zu den inficirien Verletzungen und beginne mit der

\section{Uveitis serosa traumatica.}

Ueber die Entstehung rein seröser Uvealentzündungen durch ektogene Infection ist mir aus der Literatur nichts bekannt, als ein vor zwei Jahren auf dem Utrechter internationalen Ophthalmologencongress von mir gehaltener Vortrag: „Ueber benigne postoperative Cyclitis auf infectiöser Basis“"2). Ich beschrieb hier 16 Fälle einer postoperativ aufgetretenen, chronischen, gutartigen Cyclitis mit Descemet'schen Beschlägen, die ich mit grösster Wahrscheinlichkeit auf eine zum Befeuchten der Wattetupfer benutzte, nicht keimfreie Borlösung zurückführen konnte. Aufkochen dieser Lösung vor jeder Operation bewirkte, dass diese Cyclitis nie mehr auftrat. Nach zufälligen Verletzungen habe ich diese rein seröse Form nur drei Mal beobachtet, und auch diese Fälle sind nicht vollkommen einwandstrei.

Fall 1. Dem 19jährigen Kaufmann Kurt Sch. flog am 26. VI. 1898 durch Explodiren eines Zündhütchens ein Stückchen Kupfer ins rechte Auge. Zwei Stunden später findet sich eine kleine Corneawunde, beginnende traumatische Cataract und im Glaskörper eine Luftblase und ein röthlicher Fremdkörper unten nasal. Noch am gleichen Tage wird hier in Narkose nach Tenotomie des Rectus inferior ein meridionaler Schnitt durch die Sklera gemacht. Da sich nichts einstellt, wird zunächst nach innen, dann nach aussen ein senkrechter Schnitt darauf gesetzt und die hierdureh entstandenen vier Zipfel der Reihe nach etwas umgeklappt. Beim Evertiren des letzten stellt sich eine kleine Luftblase ein und das Kupferstuekchen wird sichtbar und leicht hervorgeholt. Zwei Suturen in der Sklera,

1) Dies Phthisisch- und Empfindlichwerden durch starken Glaskörperverlust ist ein höchst interessantes und noch völlig unaufgeklärtes Phänomen. Ich sah es in einem Falle nach Staaroperation, wo ich von der Resection Abstand nahm, weil ich von der Keimfreiheit des Auges fest überzeugt war, nach einem halben Jahr von selbst wieder schwinden. Jetzt ist das betreffende Auge seit fünf Jahren reizlos und das zweite inzwischen mit gutem Erfolge extrahirt. Die Frage wird z. Z. in meiner Klinik experimentell bearbeitet.

2) Congressbericht. Amsterdam 1900. S. 402. 
Muskelnaht, eine Reile Conjunctivalnähte, Verband. Der Glaskörperverhust war nicht erheblich gewesen.

Die ersten 17 Tage ging die Heilung glatt von statten, und das Auge blasste stetig ab. Dann aber trat stärkere Injection auf, etwas Sehmerzen stellten sich ein, und vier Tage später wurde an der Lupe eine beschränkte Anzahl Descemet'scher Beschläge entdeckt. $3 \mathrm{~g}$ Salicylnatron, Schwitzen, Atropin, fenchter Verband. Hierbei ging die Entzundung allmählich zurick, und nach drei Wochen konnte Patient mit blassem reizlosen Auge entlassen werden. Die Beschläge waren resorbirt; das Sehvermögen in Folge des Staars auf Fingerzathlen in $30 \mathrm{~cm}$ redueirt.

So hat sich der Zustand gehalten. Am 15. III. 1899 war durch Resorption der Cataract, das Sehen auf Fingerzählen in $1 \frac{1}{2} \mathrm{~m}$ gestiegen. Nach allen Seiten rothes Licht; eine Discision des Nachstaars ist bisher nicht ausgeführt.

Fall 2. Dem 37jähigen Schlosser Z. flog am 3. V. 1900 ein Sthek Eisen ins rechte Auge. Er kommt am 9. V. mit rerheilter Comeawunde, traumatischer Cataract und Eisensplitter im Glaskörper. Am folgenden Tage wird derselbe durch den Schlösser'sehen grossen Magneten in dio Vorderkammer gezogen und won hier nach Hornhantschnit mit dem Hirschbergschen Magneten leicht extrahint (Gewicht $0,0028 \mathrm{~g}$ ). Glatte Heilung, doch ist das Auge bei der Entlassung am 21. VT. noch nicht völlig blass. Zn Hause entzündet es sich bald stärker, und am 2. VI, als sich Patient wieder vorstellt, findet sich stärkere pericorneale Injection und eine Anzahl theils weisser, theils schon bräunlicher Descemet'scher Beschläge. Corpus ciliare nicht druckempfindlich; aber Lichtschen und Thränenträufeln.

Zweite Aufname. Atropin, Verband und Tmunetionen mit grauer Salbe, zwei Touren zu $4 \mathrm{~g}$ und eine $\mathrm{zu} 3 \mathrm{~g}$, also $66 \mathrm{~g}$ im Ganzen. Am 26. VI. ist das Auge völig reizfrei und die Beschlige bis auf wenige dunkel gefärbte verseliwunden. Entlassung. Nach drei Monaten wird der Staar extrahirt und Patient erhält wieder $\mathrm{S} .=1 / 4$.

Fall 2 a. Der 29 jährige Steinbrecher Wilhelm B. exlitt am 28. VII. 1900 durch vorzeitige Explosion einer Mine an beiden Augen Verletzungen. Bei seiner Vorstellung am 30. VIT. fand sich ausser einer Verbrenuung des Gesichts und einigen Pulverkörnern in beiden Hornläuten eine perforirende Cornealyrunde mit Irisprolaps links, traumatische Cataract, trübes Kammerwasser und etwas verfarbte Iris. Lichtsehein und Projection ungenügend. Abtragung des Prolapses, Atropin, feuchter Verband. Hierbei geht die Injection und Verfärbung der Iris allmählich zurick und der Reizzustand schwindet, bis am 10. VIII. beim Verbandwechsel die Wunde nochmals anfgeht und das Kammerwasser abfliesst. Vier Tage danach finden sieh bei mässiog entziundetem Ange Descemet'sche Beschläge, und das Kammerwasser erscheint wieder etwas trüber. Inunctionen mit $4 \mathrm{~g}$ grauer Salbe bis zum 21. IX., im Ganzen also $96 \mathrm{~g}$; dazu Schwitzen. 14 Tage nach Beginn der Schmiercur fangen die Beschläge an, sich zu verkleinern und sind am 24. IX. bis anf einige dunkelbraune Pünktehen verschwunden. Zugleich ist das Auge blass, reizlos und nicht phthisisch, und ron dem Wundstaar ist ein grosser Theil resorbirt worden. Die Functionen blieben ungenügend. Es liegt also höehst wahrscheinlich ein Fremdkörper im hinteren Bulbusabschnitt. 
Zur Diagnose, Prognose u. Therapie d. perforir, inficirten Augapfelverletzungen. 7

In allen drei Fällen ist also nach einer perforirenden Verletzung eine chronische Cyclitis aufgetreten, deren wesentlichstes Symptom Descemet'sche Beschläge waren. Wenn ich es trotzdem nicht für sicher halte, dass dieselbe auf eine Infection bei der Verletzung zurückzufubren ist, so denke ich dabei einmal an die Fremdkörper, die sich in allen Augen fanden, und zweitens an die abermalige Eröffnung der Bulbuskapsel, die stets dem Auftreten der Descemet'schen Beschläge vorhergegangen war. Man könnte ebenso wohl auf eine hierbei stattgehabte Infection die Entzïndnng beziehen. Auch wäre das Incubationsstadium ausserordentlich lang, wenn man die Cyclitis auf Infection bei der Verletzung zurückführen wollte, nämlich 2\%, ca. 3 und 21/2 Wochen. Ganz von der Hand weisen möchte ich diese Möglichkeit aber durchaus nicht. Auch in den oben erwähnten') postoperativ aufgetretenen Fällen von Cyclitis serosa betrug das Incubationsstadium $5-12$, in einem Falle sogar 17 Tage; und die Wiedereröfnung des Bulbus, zumal im Falle 2a, könnte sehr wohl in ähnlicher Weise, wie Operationen bei chronischen Uveitiden Anlass zu Recidiven werden, hier die noch schlummernde Entzündung zum Ausbruch gebracht haben.

Es sind also diese drei Fälle zu unrein, als dass man aus ihnen die Existenz einer traumatischen, durch Infection entstandenen Cyclitis oder Uveitis serosa beweisen könnte. Dass dieselbe vorkommt, halte ich aber für zweifellos und führe als Beweis dafür die von mir nach Staaroperation beobachteten 16 Fälle an, wo es sich auch nur um eine ektogene Infection handeln konnte, und weiter die Uveitis serosa sympathica, die ebenfalls durch ektogene Infection entsteht, wenn auch bei ihr die Eingangspforte für die Mikrobien sich am anderen Auge befindet. Vielleicht haben Collegen mit einem grösseren Verletzungsmaterial $a b$ und an Gelegenheit, diese jedenfalls recht seltene Erkrankung zu beobachten. Dieselbe stellt die mildeste Form der Infection dar, hat ein langes Incubationsstadium und fithrte hier ebenso stets zur völligen Heilung, wie es die symputhische und die nach Operationen auftretende seröse Uvealentziindung thut.

\section{Uveitis fibrinosa traumatica.}

Eine häufige und allen Ophthalmologen wohlbekannte Form traumatischer Entzindung ist die fibrinöse Uveitis, deren infectiöser Ursprung nirgends mehr ernstlich geleugnet wird, wenn auch die

\footnotetext{
1) Loc. cit.
} 
meisten Autoren sich noch recht reservirt ibber diesen Punkt aussprechen ${ }^{1}$ ). Als sicher gestellt aber gilt ihre schlechte Prognose. Zumal in Riicksicht auf die drohende sympathische Entzündung empfehlen Alle, bei ausgebrochener plastischer Entzündung nicht mit der Enucleation oder Resection zu zögern (Hosch, loc. cit. S. 210), da das Auge doch verloren sei (Fick, Prann) and keine Versuche mehr zur Entfernung eines eingedrungenen Fremdkörpers zu machen (Fuchs, Lehrbuch, 4. Auf. 1894, S. 252). Unter der Herrschaft dieser Anschauungen habe auch ich anfangs eine conservative Therapie nur für kurze Zeit für gerechtfertigt gehalten und enucleirt, wenn

1) Z. B. Hoseh, Grundriss der Augenheilkunde, 1897, S. 209, Praun loe. eit, Vossius, Lehrbuch, 3. Aufl. 1848 u. A.

\begin{tabular}{|c|c|c|c|c|c|c|}
\hline Nr. & $\mathrm{J}_{\mathrm{I}}-\mathrm{Nr}$ & Name & 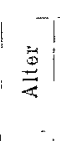 & $\begin{array}{l}\text { Art und Sitz } \\
\text { der Verletzung }\end{array}$ & \begin{tabular}{|c|}
$\mid$ Seitver- \\
letzung \\
ver- \\
fossent
\end{tabular} & $\begin{array}{l}\text { Bild der Entzündungr } \\
-\ldots-\ldots\end{array}$ \\
\hline 3 & $\begin{array}{c}1895 \\
171\end{array}$ & $\begin{array}{l}\text { Willy } \\
\text { Seh. }\end{array}$ & 6 & $\begin{array}{l}\text { Messerschnitt durch } \\
\text { ganze Cornea, Iris- } \\
\text { prolaps, Glaskörpor- } \\
\text { blutung }\end{array}$ & $1 \mathrm{Tag}$ & $\begin{array}{l}\text { Starke Injection, etwas che- } \\
\text { mose, Iris verwaschen und } \\
\text { verfärbt }\end{array}$ \\
\hline 4 & $\begin{array}{l}1895 \\
263\end{array}$ & $\begin{array}{l}\text { Heleno } \\
\text { B. }\end{array}$ & 4 & $\begin{array}{l}\text { Messerschnitt. } 7 \mathrm{~mm} \\
\text { lange Corneo-Skle- } \\
\text { ralwunde. Irispro- } \\
\text { laps }\end{array}$ & $1 / 2 \operatorname{Tag}$ & $\begin{array}{l}\text { Iris verfürbt, Pupillarexsu- } \\
\text { dat }\end{array}$ \\
\hline$\tilde{\partial}$ & $\begin{array}{l}1895 \\
224\end{array}$ & $\begin{array}{l}\text { Paul } \\
\text { T. }\end{array}$ & & $\begin{array}{l}\text { Pfeilschuss. Zipflige } \\
\text { Hornhautwunde mit } \\
\text { Irisprolaps }\end{array}$ & 1 Tag & $\begin{array}{l}\text { Iris stark verwavchen und } \\
\text { verfärbt. Reichliche fibri- } \\
\text { nöse Exsudation. Corpus } \\
\text { ciliare ditackempfindlich; } \\
\text { Tags darauf Chemose }\end{array}$ \\
\hline 6 & $\begin{array}{l}1895 \\
256\end{array}$ & $\begin{array}{l}\text { Nartha } \\
\quad G .\end{array}$ & $2 \%$ & $\begin{array}{l}\text { Schnittmit Porzellan- } \\
\text { scherbe Lappen- } \\
\text { wunde der Sklera. } \\
\text { Wundstaar }\end{array}$ & 3 Tage & $\begin{array}{l}\text { Iris verwasehen und yer- } \\
\text { färbt. Starke Injection }\end{array}$ \\
\hline 7 & $\begin{array}{l}1895 \\
322\end{array}$ & $\begin{array}{l}\text { Paul } \\
\text { S. }\end{array}$ & 9 & $\begin{array}{l}\text { Gabelstich. } 2 \text { Löcher } \\
\text { in Cornea u. Shlera. } \\
\text { Irisprolaps, Wund- } \\
\text { staar }\end{array}$ & 2 Tage & $\begin{array}{l}\text { Starke Injection, Iris rer- } \\
\text { verwaschen }\end{array}$ \\
\hline 8 & $\begin{array}{l}1895 \\
3 \pm 7\end{array}$ & $\begin{array}{l}\text { Franz } \\
\text { Schr. }\end{array}$ & 30 & $\begin{array}{l}\text { Algesprungen. Stahl- } \\
\text { stück. Corneawunde, } \\
\text { Irisprolaps }\end{array}$ & $1 \mathrm{Tag}$ & $\begin{array}{l}\text { Iris verwaschen, verfärbt; } \\
\text { reagirt schlechtauf Atropin }\end{array}$ \\
\hline 9 & $\begin{array}{l}1895 \\
334\end{array}$ & $\begin{array}{l}\text { Christoph } \\
\text { K. }\end{array}$ & 22 & $\begin{array}{l}\text { Abgesprung. grosses } \\
\text { Holzstück. Comea- } \\
\text { wunde, Trisyrolaps }\end{array}$ & $1 \mathrm{Tag}$ & $\begin{array}{l}\text { Etwas spontaner und Druek- } \\
\text { schmerz. Starke Injection. } \\
\text { Iris stark verfärbt und rer- } \\
\text { waschen }\end{array}$ \\
\hline
\end{tabular}


Zur Diagnose, Prognose u. Therapie d. perforix., inficirten Augapfelverletzungen. $\quad 9$

sich vicht bald eine entschiedene Wendung zum Besseren zeigte. Erst almählich, durch die ersten Erfolge ermuthigt, schob ich die Enucleation weiter und weiter hinaus und hatte die Freude, manches Auge zu retten, das ich früher für sicher verloren gehalten hätte, während ich auf der anderen Seite nicht einen Fall von sympathischer Fntzündung bei dieser Behandlungsweise zu beklagen hatte. So bin ich allmählich zu dem Resultat gekommen, über die Hälfte dieser Augen mit einem Theil ihres Sehvermögens zu erhalten, während von gleichartig erkrankten Augen, die noch ohne $\mathrm{Hg}$ behandelt wurden, nur ein einziges erhalten wurde, bei dem die Fntzündung von vorn herein sehr milde auftrat.

Ehe ich auf Finzelheiten eingehe, gebe ich in tabellarischer Uebersicht die Krankengeschichten von 39 hierher gehörigen Fällen.

\begin{tabular}{|c|c|c|c|}
\hline $\begin{array}{c}\text { Behandlungsweise, } \\
\text { (Selbstredend wberall Atropin, } \\
\text { Verband, Bedtruhe) }\end{array}$ & $\begin{array}{l}\text { Daner } \\
\text { der Behandiung }\end{array}$ & Resultat & Bemerknngen \\
\hline $\begin{array}{l}\text { Prolaps abgetragen, zwei } \\
\text { Corneasuturen. Hg-Inunc- } \\
\text { tionen, zunächst } 4 g \text {, spater } \\
2 g \text { pro die. - } 36 \mathrm{~g} \text { Ung. } \\
\text { cin. in toto }\end{array}$ & 5 Wochen & $\begin{array}{l}\text { Geheilt. } \\
\mathrm{S} .=1 / 6\end{array}$ & $\begin{array}{l}\text { Nach } 2 \text { Jahren } S .=1 / 7 \\
\text { Kleiner hinterer Po- } \\
\text { larstaar }\end{array}$ \\
\hline $\begin{array}{l}\text { Prolaps abgetragen, Con- } \\
\text { junctivalplastik. Kein Hg }\end{array}$ & $4^{1 / 2}$ Woche & $\begin{array}{l}\text { Auge reizlos. } \\
\text { Leichte Phthise }\end{array}$ & $\begin{array}{l}\text { Die iritischen Exschei- } \\
\text { nungen traten erst am } \\
\text { achten Tage auf }\end{array}$ \\
\hline $\begin{array}{l}\text { Iris abgetragen. Comeal- } \\
\text { naht. Sublimat subconjunc- } \\
\text { tival. - Inunctionen } 4 \mathrm{~g} \text {. } \\
-12 \mathrm{~g} \text { Ung. cin. in toto }\end{array}$ & Nach 3 Tagen & Enucleation & $\begin{array}{l}\text { Die Section ergiebt } \\
\text { eitrige Infiltration des } \\
\text { Glaskörpers }\end{array}$ \\
\hline $\begin{array}{l}\text { Skleral- und Conjunctival- } \\
\text { naht. - Inunctionen } 2 \mathrm{~g} \\
10 \text { Tage lang. - } 20 \mathrm{~g} \text { Ung. } \\
\text { cin. }\end{array}$ & $2^{1 / 2}$ Woche & $\begin{array}{l}\text { Geheilt. } \\
\mathrm{S} .=\frac{1}{\infty} \text { wegen } \\
\text { Staar }\end{array}$ & \\
\hline $\begin{array}{l}\text { Inunctionen } 6 \mathrm{~g} \text { pro die, } \\
4 \text { Tage lang. Später Ex- } \\
\text { traction. }-24 \mathrm{~g} \text { Ung. cin. }\end{array}$ & 4. Wochen & $\begin{array}{c}\text { Geheilt. } \\
+13 \mathrm{DS}=1 / 2\end{array}$ & \\
\hline $\begin{array}{l}\text { Prolaps abgetragen. Con- } \\
\text { junctivalplastik. } 3 \times \text { täg- } \\
\text { lich } 3 \mathrm{~g} \mathrm{Hg} \text { gerieben } 4 \text { Tage } \\
\text { lang. } 36 \mathrm{~g} \text { Ung. cin. }\end{array}$ & $2 \%$ Woche & $\begin{array}{l}\text { Geheilt. } \\
\text { S. }=1 / 3\end{array}$ & \\
\hline $\begin{array}{l}\text { Prolaps abgetragen. Zwei } \\
\text { Oorneanähte. } 3 \times \text { täglich } \\
3 \mathrm{~g} \mathrm{Hg} \text { gerieben } 6 \text { Tage } \\
\text { hindurch. Gingivitis. } \\
54 \mathrm{~g} \text { Ung. cin. }\end{array}$ & 5 Wochen & $\begin{array}{l}\text { Auge reizlos. } \\
\text { Leichte Phthisis }\end{array}$ & \\
\hline
\end{tabular}




\begin{tabular}{|c|c|c|c|c|c|c|}
\hline Nr. & J,- $\mathbb{N}_{\mathrm{r}}$ & Namo & $\stackrel{\vec{E}}{\rightleftarrows}$ & $\begin{array}{l}\text { Art und Sitz } \\
\text { der Verletzung }\end{array}$ & $\begin{array}{l}\text { Seit for- } \\
\text { letzung } \\
\text { yer- } \\
\text { flossent? }\end{array}$ & Bind lor Entzundung \\
\hline 10 & $\begin{array}{c}1896 \\
388\end{array}$ & $\begin{array}{c}\text { Hedwig } \\
\text { B. }\end{array}$ & 2 & $\begin{array}{l}\text { Wurf. Grosse Cornea- } \\
\text { wunde }\end{array}$ & $1 \mathrm{Tag}$ & $\begin{array}{l}\text { Wandränder stark intiltrirt. } \\
\text { Kammerwasser trüb, Iris } \\
\text { verfärbt nuld verwaschen. } \\
\text { Starke Injection }\end{array}$ \\
\hline 11 & $\begin{array}{l}1896 \\
421\end{array}$ & $\begin{array}{l}\text { Albert } \\
\text { Th. }\end{array}$ & & $\begin{array}{l}\text { Stockschlag. Grosse } \\
\text { Corneawunde, Iris- } \\
\text { adhäsion, Wund- } \\
\text { staar }\end{array}$ & 8 Tage & $\begin{array}{l}\text { Wunde fibrinös belegt, Iris } \\
\text { rerfürbt, verwaschen, Yu- } \\
\text { pillarexsudat, starke In- } \\
\text { jection, Hypotonie }\end{array}$ \\
\hline 12 & $\begin{array}{l}1896 \\
470\end{array}$ & $\begin{array}{l}\text { Wilhem } \\
\text { L. }\end{array}$ & 47 & $\begin{array}{l}\text { Abgesprungen. Stah- } \\
\text { stück. Skleralwunde. } \\
\text { Splitter und reich- } \\
\text { liche Trubmgen im } \\
\text { Glaskiorper }\end{array}$ & 5 Tage & $\begin{array}{l}\text { Lamnerwasser getrubt, Iris } \\
\text { verfarbt wnd verwaschen, } \\
\text { fupllityexndat. Starke h- } \\
\text { jection }\end{array}$ \\
\hline 13 & $\begin{array}{c}1896 \\
66\end{array}$ & $\begin{array}{l}\text { Käthe } \\
\text { W. }\end{array}$ & 4 & $\begin{array}{l}\text { Abgesprungen. Stein-1 } \\
\text { stück. Grosse Cor- } \\
\text { nea-Skleral wunde } \\
\text { mit Iris- und Glas- } \\
\text { körperprolaps }\end{array}$ & $1 / 2$ Tag & $\begin{array}{l}\text { Starke Injection, Iritis mit } \\
\text { Pupillarexsudat. }\end{array}$ \\
\hline 14 & $\begin{array}{c}1896 \\
87 \\
\text { u. } \\
202\end{array}$ & $\begin{array}{l}\text { Gustar } \\
\text { K. }\end{array}$ & 17 & $\begin{array}{l}\text { Abgesprungen. Holz-: } \\
\text { stück. Corneo-Skle- } \\
\text { ralwunde, Glaskör- } \\
\text { per- und Uveapro- } \\
\text { laps. Wundstaar. }\end{array}$ & 2 Tage & $\begin{array}{l}\text { Starke, lang anhaltende ln- } \\
\text { jection. Kanmerwasser } \\
\text { twib, Tris leicht verwaschen } \\
\text { und rerfarbt }\end{array}$ \\
\hline 15 & $\begin{array}{c}1896 \\
100\end{array}$ & $\begin{array}{l}\text { Wilhelm } \\
\text { Z. }\end{array}$ & 20 & $\begin{array}{l}\text { Algesprung. grosses } \\
\text { - Stahlstück. Corneo- } \\
\text { Skleralwunde, Uvea- } \\
\text { prolaps }\end{array}$ & 2 Tage & $\begin{array}{l}\text { Langdauernde Tnjection, Iris } \\
\text { leicht verfärbt und ver- } \\
\text { waschen, granes Glaskör- } \\
\text { perexsudat und fächerför- } \\
\text { mige Glaskönerstränge }\end{array}$ \\
\hline 16 & $\begin{array}{c}1896 \\
103\end{array}$ & $\begin{array}{l}\text { Fritz } \\
\text { Tl. }\end{array}$ & 28 & $\begin{array}{l}\text { Schlag. Grosse Skle- } \\
\text { ralruptur mit Uvea- } \\
\text { und Glaskörperpro- } \\
\text { laps. Linse aus dem } \\
\text { Bubus luxirt }\end{array}$ & $\begin{array}{l}21 / 2 \\
\text { Tage }\end{array}$ & $\begin{array}{l}\text { Langlanernde heftige Injec- } \\
\text { tion. Iris die ersten acht } \\
\text { Tage durch Blut verdeckt, } \\
\text { dann verfärbt wnd rer- } \\
\text { waschen }\end{array}$ \\
\hline 17 & $\begin{array}{l}1896 \\
113\end{array}$ & $\begin{array}{l}\text { Minna } \\
\text { Br. }\end{array}$ & 22 & 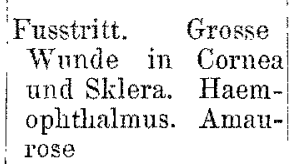 & 5 Tage & $\begin{array}{l}\text { Starke Injection. Ciliar- } \\
\text { gegend spontan wa auf Druck } \\
\text { schmerzhaft. Hintere Syn- } \\
\text { echien, Pupillarexsudat }\end{array}$ \\
\hline
\end{tabular}


Zur Diagnose, Prognose u. Therapie d. perforix., inticirten Augapfelverletzungen. 11

\begin{tabular}{|c|c|c|c|}
\hline $\begin{array}{l}\text { Behandlungsweise. } \\
\text { (Selbstredond unberall Atropin, } \\
\text { Verband, Battrutse) }\end{array}$ & $\begin{array}{c}\text { Dauer } \\
\text { der Behandlung }\end{array}$ & Resultat & Bemerkungen \\
\hline $\begin{array}{l}\text { Wundränder verschorft. } 3 \\
\times \text { täglich } 1 \mathrm{~g} \text { Hg gerieben } \\
5 \text { Tage hindurch; nach } 4 \\
\text { Tagen nochmals } 2 \mathrm{~g} \text { pro die } \\
\text { 14 Tage lang. - } 43 \mathrm{~g} \text { Ung. } \\
\text { cin. }\end{array}$ & 4 Wochen & $\begin{array}{l}\text { Geheilt. } \\
\text { Auge reizlos, } \\
\text { Druck normal, } \\
\text { Pupille gut zu } \\
\text { durchleuchten }\end{array}$ & $\begin{array}{l}\text { Nach dem ersten Aus- } \\
\text { setzen des Hg Reci- } \\
\text { div der Iritis }\end{array}$ \\
\hline $\begin{array}{l}\text { Bei Atropin und Verband } \\
\text { Rückgang der Iritis. Nach } \\
\text { 5 Wochen Iridektomie. Re- } \\
\text { cidiv der Iritis. - Kein } \mathrm{Hg}\end{array}$ & 8 Wochen & $\begin{array}{l}\text { Resectio op- } \\
\text { tico-ciliaris } \\
\text { wegen Phthisis } \\
\text { incipiens }\end{array}$ & $\begin{array}{l}\text { Die zu frühe Iridek- } \\
\text { tomie hat den fast } \\
\text { gehellten Bulbus rer- } \\
\text { nichtet }\end{array}$ \\
\hline $\begin{array}{l}\text { Ein Extractionsversuch mit } \\
\text { IIrsch berg's Magnet } \\
\text { misslingt. } 3 \text { galicylnatron, } \\
\text { Schwitzen. Nach } 14 \text { Tagen } \\
\mathrm{S} \text {. } 1 / 3 \text {. Nach } 41 / 2 \text { Wochen } \\
\text { zweiterExtractionscersuch; } \\
\text { gelingt. Aber Ablatio re- } \\
\text { tinae. Lein Hg }\end{array}$ & 7 Wochen & $\begin{array}{l}\text { Auge reizlos. } \\
\text { Hand } \\
\text { bewegungen. } \\
\text { Nach } 3 \text { Monaten } \\
\text { Status idem. }\end{array}$ & $\begin{array}{l}\text { Die Iritis war geh eilt. } \\
\text { Das Resultatist durch } \\
\text { die zweite zu früh } \\
\text { vorgenommene Ex- } \\
\text { traction verdorben }\end{array}$ \\
\hline $\begin{array}{l}\text { Abtragung von Iris und Glas- } \\
\text { körper; Suturell. }-2 \times \\
2 \mathrm{~g} \mathrm{Hg} \text { pro die, später we- } \\
\text { niger. }-48 \mathrm{~g} \text { Ung. cin. }\end{array}$ & $51 / 2$ Woche & $\begin{array}{c}\text { Geheilt. } \\
\text { Auge reizlos, } \\
\text { gutes rothes Licht. } \\
\text { Etwas Staar- } \\
\text { trubung }\end{array}$ & $\begin{array}{l}\text { Nach } 4 \text { Wochen Status } \\
\text { idem }\end{array}$ \\
\hline $\begin{array}{l}\text { Prolaps abgetragen; Wund- } \\
\text { ründer cauterisirt. }-2 \times \\
\text { täglich } 3 \mathrm{~g} \mathrm{Hg}-12 \mathrm{~g} \text { Ung. } \\
\text { cin. }\end{array}$ & 4 Wochen & $\begin{array}{l}\text { Geheilt. } \\
\text { Ange reizlos. } \\
\text { S. }=\frac{1}{\infty} \text { wegen } \\
\text { Staar }\end{array}$ & $\begin{array}{l}\text { Nach } 7 \text { Wochen Ex- } \\
\text { traction. Glatte He:- } \\
\text { lung, aber nur Finger } \\
\text { in } 1 \mathrm{~m} \text { wegen Glas- } \\
\text { körpertrübungen. } \\
\text { Besserung zu erwar- } \\
\text { ten }\end{array}$ \\
\hline $\begin{array}{r}\text { Prolaps abgetragen, Con- } \\
\text { junctivalplastik. \& } \times 3 \mathrm{~g} \\
\mathrm{Hg} \text { pro die, später } 4 \mathrm{~g} \mathrm{Hg} \\
\text { pro die. }-114 \mathrm{~g} \text { Ung. cin. }\end{array}$ & 8 Wochen & $\begin{array}{l}\text { Geheilt. } \\
\text { S. }=1 / 3, \text { Se frei. } \\
\text { Glaskörper fast } \\
\text { völlig geklärt }\end{array}$ & \\
\hline $\begin{array}{l}\text { Abtragung, Suturen durch } \\
\text { Sklera und Conjunctiva. } \\
2 \times 3 \mathrm{~g} \mathrm{Hg} 12 \text { Tage hin- } \\
\text { durch. Später Schwitzen. } \\
-54 \mathrm{~g} \text { Ung. cin. }\end{array}$ & 4 Wochen & $\begin{array}{l}\text { Geheilt } \\
+8 \mathrm{D} \mathrm{S} .>^{1 / 4} \\
\text { Reste von Glas- } \\
\text { lrörpertrübung. }\end{array}$ & \\
\hline $\begin{array}{l}\text { Reinigung. Atropin, Ver- } \\
\text { band. Kein } \mathrm{Hg}\end{array}$ & 4 Wochen & $\begin{array}{l}\text { Enucleation } \\
\text { wegen Phthisis } \\
\text { dolorosa }\end{array}$ & $\begin{array}{l}\text { Bulbus schien von } \\
\text { vorn herein verloren. } \\
\text { Die Section ergiebt } \\
\text { fibrinöse Entzundung } \\
\text { mit Schwartenbildung }\end{array}$ \\
\hline
\end{tabular}




\begin{tabular}{|c|c|c|c|c|c|c|}
\hline Nir. & J.-Nr. & $\operatorname{San} \theta$ & 急 & $\begin{array}{l}\text { Art und Sitz } \\
\text { der Verletzung }\end{array}$ & $\begin{array}{l}\text { Seit Ver- } \\
\text { letzung } \\
\text { ver- } \\
\text { Hessen? }\end{array}$ & Bild der Entzündung \\
\hline 18 & $\begin{array}{l}1896 \\
184\end{array}$ & $\begin{array}{l}\text { Karl } \\
\text { M. }\end{array}$ & 15 & $\begin{array}{l}\text { Steinwurf. Slleral- } \\
\text { wunde mit Trispro- } \\
\text { laps }\end{array}$ & 1 Tag & $\begin{array}{l}\text { Starke Injection, Iris ver- } \\
\text { waschen }\end{array}$ \\
\hline 19 & $\begin{array}{l}1896 \\
259\end{array}$ & $\begin{array}{l}\text { Willy } \\
\text { St. }\end{array}$ & 5 & $\begin{array}{l}\text { Mit Topfscherbe ge- } \\
\text { schnitten. Corneo- } \\
\text { Skleralwunde. Iris- } \\
\text { und Glaskörperpro- } \\
\text { laps }\end{array}$ & 9 Tage & $\begin{array}{l}\text { Nässige Injection. Iris ver- } \\
\text { waschen und verfärbt. Sy- } \\
\text { nechien }\end{array}$ \\
\hline 20 & $\begin{array}{l}1896 \\
362\end{array}$ & $\begin{array}{l}\text { Wilhelm } \\
\text { M. }\end{array}$ & 43 & $\begin{array}{l}\text { Abgesprungen. Stein- } \\
\text { stück. } \\
\text { wunde. } \\
\text { Hornhaut- Wundstaar }\end{array}$ & 2 Tage & $\begin{array}{l}\text { Wundränder infiltrirt. Iris } \\
\text { verfärbt und rerwaschen }\end{array}$ \\
\hline 21 & $\begin{array}{l}1897 \\
241\end{array}$ & $\begin{array}{l}\text { Wilhelm } \\
\text { St. }\end{array}$ & 60 & $\begin{array}{l}\text { Abgespringen. Holz- } \\
\text { stück. Corneawunde, } \\
\text { Irisprolaps }\end{array}$ & 8 Tage & $\begin{array}{l}\text { Wundrander infiltrirt. } \\
\text { Graues Exsudat und Blut } \\
\text { in Vorderkammer. Nach } \\
\text { 14 Tagen Ciliarkörper } \\
\text { spontan und auf Druck } \\
\text { schmerzhaft }\end{array}$ \\
\hline 22 & $\begin{array}{l}1897 \\
273\end{array}$ & $\begin{array}{l}\text { Friedrich } \\
\quad L .\end{array}$ & 17 & $\begin{array}{l}\text { Abgesprungener } \mathrm{Na} \\
\text { gel. Corneawunde, } \\
\text { Staar, Glaskörper- } \\
\text { prolaps }\end{array}$ & $1 \mathrm{Tag}$ & $\begin{array}{l}\text { Wundränderinfiltrirt; starke } \\
\text { Injection; Iris anfangs } \\
\text { dureh Blut yerdeckt. Später } \\
\text { ihre Peripherie retrahirt. } \\
\text { Corpus ciliare leicht druck- } \\
\text { emptindlich }\end{array}$ \\
\hline 23 & $\begin{array}{l}1897 \\
426\end{array}$ & $\begin{array}{l}\text { Marie } \\
\text { Gr. }\end{array}$ & 36 & $\begin{array}{l}\text { Scheerenstich, Cor- } \\
\text { neawunde, Irispro- } \\
\text { laps, Wundstaar }\end{array}$ & 2 Tage & $\begin{array}{l}\text { Starke Injection, etwas Che- } \\
\text { mose. Wundrändex infil- } \\
\text { trirt. Iris verfärbt und ver- } \\
\text { waschen, Kammerwasser } \\
\text { trüb, Pupillarexsudat }\end{array}$ \\
\hline 24 & $\begin{array}{l}1898 \\
349\end{array}$ & $\begin{array}{l}\text { Wilhelm } \\
\text { L. }\end{array}$ & 52 & $\begin{array}{l}\text { Kuhhornstoss. Grosse } \\
\text { Skleralruptur, Iris- } \\
\text { vorfall. Linse nach } \\
\text { aussen luxirt. Glas- } \\
\text { körperblutung }\end{array}$ & 3 Tage & $\begin{array}{l}\text { Starke Injection, etwas Che- } \\
\text { mose. Iris verfärbt, rer- } \\
\text { waschen. Prolaps sient } \\
\text { etwas eitrig aus }\end{array}$ \\
\hline 25 & $\begin{array}{l}1898 \\
448\end{array}$ & $\begin{array}{l}\text { Max } \\
\text { KI. }\end{array}$ & 17 & $\begin{array}{l}\text { Abgesprung. Eisen-. } \\
\text { stück Corneawunde, } \\
\text { Glaskürpervorfall, } \\
\text { Eisen im Glas- } \\
\text { körper }\end{array}$ & $1 / 2 \mathrm{Tag}$ & $\begin{array}{l}\text { Etwas Chemose, Kammer- } \\
\text { wasser trübe. Iris ver- } \\
\text { waschen, rerfärbt. Ciliar- } \\
\text { korper spontan und auf } \\
\text { Druck empfindlich. Nach } \\
\text { zwei Wochen Iypotonie }\end{array}$ \\
\hline 26 & $\begin{array}{l}1898 \\
592\end{array}$ & $\begin{array}{l}\text { Paul } \\
\text { B. }\end{array}$ & 4 & $\begin{array}{l}\text { Schuss mit Blasrohr- } \\
\text { pfeil. Cornealwunde. } \\
\text { Wundstaar }\end{array}$ & 4 Tage & $\begin{array}{l}\text { Wundränder gelbgrau infil- } \\
\text { trirt. Iris verfärbt und } \\
\text { verwaschen }\end{array}$ \\
\hline 27 & $\begin{array}{l}1898 \\
536\end{array}$ & $\begin{array}{l}\text { Beate } \\
\text { K. }\end{array}$ & 5 & $\begin{array}{l}\text { Scheerenstich. Cor- } \\
\text { neo-Skleralwunde }\end{array}$ & 5 Tage & $\begin{array}{l}\text { Wundränder gelblich infil- } \\
\text { trirt. Exsudat in Vorder- } \\
\text { kammer. Corpus eiliare } \\
\text { druckempfindlich }\end{array}$ \\
\hline
\end{tabular}


Z ur Diagnose, Prognose u. Therapie d. jerforir., inficirten Augapfelverletzungen. 13

\begin{tabular}{|c|c|c|c|}
\hline $\begin{array}{l}\text { Behtndidurgstreise. } \\
\text { (Selbstredend unberall Atropin, } \\
\text { Verband, Bettruhe) }\end{array}$ & $\begin{array}{c}\text { Daner } \\
\text { der Bebandlung }\end{array}$ & Resultat & Bemerkungen \\
\hline $\begin{array}{l}\text { Prolaps abgetragen. Con- } \\
\text { junctivalnahte. } 2 \times 3 \mathrm{~g} \mathrm{Hg} \\
\text { täglich für } 6 \text { Tage. }-36 \mathrm{~g} \\
\text { Ung. cin. }\end{array}$ & 3 Wochen & $\begin{array}{l}\text { Geheilt } \\
\text { S. }=1 / 3\end{array}$ & \\
\hline $\begin{array}{l}\text { Abtragung, Conjunctival- } \\
\text { plastik. } 2 \times 3 g \mathrm{Hg} \text { pro die. } \\
\text { Wie lange? }\end{array}$ & 4. Wochen & $\begin{array}{l}\text { Reizlose } \\
\text { Phthise }\end{array}$ & \\
\hline $\begin{array}{l}\text { Atropin, Verband. Nach } 14 \\
\text { Tagen Extraction. Kein Hg. }\end{array}$ & 7 Wochen & $\begin{array}{l}\text { Geheilt. } \\
+10 \mathrm{DS}=1 / 5\end{array}$ & \\
\hline $\begin{array}{l}\text { Abtragung. Schwitzen, Sa- } \\
\text { licylnatron } 2 \mathrm{~g} \text { pro die }\end{array}$ & 6 Wochen & $\begin{array}{l}\text { Bulbus reizlos, } \\
\text { leicht phthisisch }\end{array}$ & $\begin{array}{l}\text { Nach } 3 \text { Wochen Giliar- } \\
\text { körper leicht em- } \\
\text { pfindlich. Enucleation } \\
\text { verweigert }\end{array}$ \\
\hline $\begin{array}{l}\text { Abtragung, } 2 \times 3 \mathrm{~g} \mathrm{Hg} \text { pro } \\
\text { die } 14 \text { Tage lang, } 3 \text { Wochen } \\
\text { Salicylnatron } 3 \mathrm{~g} \text { pro die, } \\
2 \text { Touren } \mathrm{Hg} z \mathrm{zu} 5 \text {. Koch- } \\
\text { salzinjectionen. - } 114 \mathrm{~g} \\
\text { Ung. cin. }\end{array}$ & 9 Wochen & $\begin{array}{l}\text { Resectio op- } \\
\text { tico-ciliaris } \\
\text { wegen Phthisis } \\
\text { dolorosa }\end{array}$ & \\
\hline $\begin{array}{l}\text { Wunde canterisirt, Kammer } \\
\text { punktirt. } 2 \times 3 \mathrm{~g} \mathrm{Hg} \text { pro } \\
\text { die } 8 \text { Tage hindurch. Sto- } \\
\text { matitis, Exanthem. }-42 \mathrm{~g} \\
\text { Ung. cin. Nach } 4 \text { Wochen } \\
\text { Extraction. }\end{array}$ & 6 Wochen & $\begin{array}{l}\text { Geheilt. } \\
\text { S. }=\frac{1}{\infty} \text { wegen } \\
\text { Nachstaax }\end{array}$ & $\begin{array}{l}\text { Nach } 3 \text { Monaten Dis- } \\
\begin{array}{l}\text { cision. } \\
\text { S. }=2 / 3\end{array}\end{array}$ \\
\hline $\begin{array}{l}\text { Abtragung, Cauterisation, } \\
\text { Conjunctivalnähte. } 2 \times 3 \mathrm{~g} \\
\mathrm{Hg} \text { pro die. - Wie lange? }\end{array}$ & $61 / 2$ Wochen & $\begin{array}{l}\text { Geheilt } \\
+12 \mathrm{DS}=1 / 8\end{array}$ & $\begin{array}{l}\text { Nach } 4 \text { Wochen Auge } \\
\text { gutgeblieben. } \mathrm{S}=1 / 6\end{array}$ \\
\hline $\begin{array}{l}\text { Extraction mit kleinem } \\
\text { Magneten. } 2 \times 4 \mathrm{~g} \mathrm{Hg} \text { pro } \\
\text { die } 15 \text { Tage hindurch. } 10 \\
\text { Sublimatinjectionen sub- } \\
\text { conjunctival. }-96 \mathrm{~g} \text { Ung. } \\
\text { cin. }\end{array}$ & $2^{1 / 2}$ Wochen & $\begin{array}{c}\text { Enucleation } \\
\text { bei beginnender } \\
\text { Atrophia bulbi }\end{array}$ & $\begin{array}{l}\text { Die Section ergiebt } \\
\text { einen Abscess im } \\
\text { Glaskörper }\end{array}$ \\
\hline $\begin{array}{l}\text { Erst } 4 \mathrm{~g} \text {, dann } 3 \mathrm{~g} \mathrm{Hg} \text { pro die. } \\
\text { NaCl-Injectionen. }-42 \mathrm{~g} \\
\text { Ung. cin. }\end{array}$ & 4 Wochen & $\begin{array}{l}\text { Geheilt. } \\
\mathrm{V} .=\frac{1}{\infty} \text { wegen } \\
\text { Staar }\end{array}$ & $\begin{array}{l}\text { Nach } 2 \text { Monaten Dis- } \\
\text { cision; kleine Lücke }\end{array}$ \\
\hline $\begin{array}{l}4 \mathrm{~g} \mathrm{Hg} \text { pro die. }-16 \mathrm{~g} \text { Ung. } \\
\text { cin. }\end{array}$ & $\begin{array}{l}\text { Nach } \\
5 \text { Tagen }\end{array}$ & Enucleation & $\begin{array}{l}\text { Section ergiebt Ver- } \\
\text { eiterung des vorderen } \\
\text { Glaskörperabschnittes }\end{array}$ \\
\hline
\end{tabular}




\begin{tabular}{|c|c|c|c|c|c|c|}
\hline Nr. & $J . N r$ & Name & 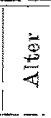 & $\begin{array}{l}\text { Art und Sitz } \\
\text { der Verletzmig }\end{array}$ & $\begin{array}{l}\text { Soit Ver- } \\
\text { letzung } \\
\text { rer- } \\
\text { flossen? }\end{array}$ & Bild lev Entzindung \\
\hline 28 & $\mid \begin{array}{c}1899 \\
512\end{array}$ & $\begin{array}{l}\text { Wilhelm } \\
\text { B. }\end{array}$ & 27 & $\begin{array}{l}\text { Abgesprung. Eisen- } \\
\text { stick, Skleral wunde, } \\
\text { Ureaprolaps, Eisen } \\
\text { im Glaskörper, Rand } \\
\text { in der Wunde ein- } \\
\text { gekeilt }\end{array}$ & 1/2 Tag & $\begin{array}{l}\text { Starke Injection. Iris ver- } \\
\text { raschen, verfarbt, Iupillar- } \\
\text { exsudat, graues Exsudat im } \\
\text { Glaskörper }\end{array}$ \\
\hline 29 & $\begin{array}{l}1899 \\
115\end{array}$ & $\begin{array}{l}\text { Albert } \\
\text { N. }\end{array}$ & 6 & $\begin{array}{l}\text { Schuss mit Flitz- } \\
\text { bogenpfeil. Cornea- } \\
\text { lappenwunde, Tris- } \\
\text { prolaps, Wundstane }\end{array}$ & $1 \mathrm{Tag}$ & $\begin{array}{l}\text { Starke Injection, Iris rer- } \\
\text { farbt, Exsudat in Vorder- } \\
\text { kitmmer }\end{array}$ \\
\hline 30 & $\begin{array}{l}1899 \\
219\end{array}$ & $\begin{array}{l}\text { Joseph } \\
\text { R. }\end{array}$ & 24 & $\begin{array}{c}\text { Messerstich. Grosse } \\
\text { Corneo-Skleral- } \\
\text { wunde, Staar }\end{array}$ & 1/2 Tag & $\begin{array}{l}\text { Injection, etwas Chemose. } \\
\text { Iris rerfärbt und verwa- } \\
\text { schen; länger dauernde Hy- } \\
\text { potonie }\end{array}$ \\
\hline 31 & $\begin{array}{c}1899 \\
272\end{array}$ & $\begin{array}{l}\text { Wilhelm } \\
\text { N. }\end{array}$ & 43 & $\begin{array}{l}\text { hubhornstoss. Grosse } \\
\text { Skleralruptur }\end{array}$ & 14 Tage & $\begin{array}{l}\text { Injection, Iris stark verfärbt } \\
\text { und verwaschen, Pupillar- } \\
\text { exsudat. Corpus ciliare } \\
\text { spontan und druckempfind- } \\
\text { iich }\end{array}$ \\
\hline 32 & $\begin{array}{l}1899 \\
297\end{array}$ & $\begin{array}{l}\text { Walther } \\
\text { D. }\end{array}$ & 4 & $\begin{array}{l}\text { Scheerenstich. Cor- } \\
\text { neawunde, Irispro- } \\
\text { laps }\end{array}$ & 2 Tage & $\begin{array}{l}\text { Langdauernde Injection, Iris } \\
\text { verfarbt, hintere Syne- } \\
\text { chien, keine Schmerzlaftig- } \\
\text { keit, Hypotonie }\end{array}$ \\
\hline 33 & $\begin{array}{c}1899 \\
406\end{array}$ & $\begin{array}{l}\text { Paul } \\
\text { B. }\end{array}$ & 15 & $\begin{array}{c}\text { Scheerenstich. Cor- } \\
\text { neawunde, Irispro- } \\
\text { laps, Wundstaar }\end{array}$ & 2 Tage & $\begin{array}{l}\text { Iris stark rerwaschen und } \\
\text { verfärbt; grosses, ziemlich } \\
\text { dichtes Pupillarexsudat. } \\
\text { Corpusciliare leicht druch- } \\
\text { empfindlich. Nach drei } \\
\text { Wochen bilden sich gelb- } \\
\text { rothliche Granulationsmas- } \\
\text { sen hinter der Wunde, die } \\
\text { sich später wieder resorbi- } \\
\text { ren. Zeitweise Hypotonie. }\end{array}$ \\
\hline 34 & $\begin{array}{c}1899 \\
424\end{array}$ & $\begin{array}{l}\text { Panl } \\
\mathrm{H} .\end{array}$ & & $\begin{array}{c}\text { Messerschnitt. Grosse } \\
\text { Corneo-Skleral - } \\
\text { wunde, Wundstaar } \\
\text { ! }\end{array}$ & $1 \mathrm{Tag}$ & $\begin{array}{l}\text { Anfangs Infection nicht } \\
\text { sicher. Nach acht Tagen } \\
\text { stärkere Injection und et- } \\
\text { was Schmerz. Irisverän- } \\
\text { derungen sehr gering, aber } \\
\text { röthliche Granulationswa- } \\
\text { cherung an der Wunde. } \\
\text { Hypotonie }\end{array}$ \\
\hline 35 & $\begin{array}{l}1900 \\
588\end{array}$ & $\begin{array}{l}\text { Karl } \\
\mathrm{P}\end{array}$ & 16 & $\begin{array}{l}\text { Schnittwande der } \\
\text { Hornlraut. Wund- } \\
\text { staar }\end{array}$ & 4 Tage & $\begin{array}{l}\text { Iris stark vertärbt und ver- } \\
\text { waschen. Pupillarexsudat. } \\
\text { Nach } 30 \text { Tagen gelbliche } \\
\text { Granulationen hinter der } \\
\text { Wunde. Hypotnnie }\end{array}$ \\
\hline
\end{tabular}


Zur Diagnose, Prognose u. Therapie d. perforir., inficirten Angapfelverletzungen. 15

\begin{tabular}{|c|c|c|c|}
\hline $\begin{array}{l}\text { Behandlungsweise. } \\
\text { (Selbstredend ûberall Atropin, } \\
\text { Verband, Bettrnhe) }\end{array}$ & $\begin{array}{c}\text { Dauer } \\
\text { der BehandIung }\end{array}$ & Resultat & Bemerkungen \\
\hline $\begin{array}{l}\text { Extraction mitPincette. Ge- } \\
\text { wicht } 670 \mathrm{mg}(1) \text {. Conjunc- } \\
\text { tivalplastik, } 2 \times 3 \mathrm{~g} \mathrm{Hg} \\
\text { pro die } 6 \text { Tage hindurch. } \\
\text { Jodkalium. }-36 \mathrm{~g} \text { Ung. cin. }\end{array}$ & 3 Wochen & $\begin{array}{l}\text { Geheilt. } \\
\mathrm{S} .=1 / 10\end{array}$ & $\begin{array}{l}\text { Nach } 11 / 2 \text { Jahren wollig } \\
\text { Status idem }\end{array}$ \\
\hline $\begin{array}{l}\text { Prolaps abgetragen. } \mathrm{Hg} 4 \mathrm{~g} \\
\text { pro die } 6 \text { Tage, nach } 5 \\
\text { tägiger Pause nochmals } \\
\text { 12Tage. }-72 \mathrm{~g} \text { tng. cin. }\end{array}$ & 4. Wochen & $\begin{array}{c}\text { Geheilt. } \\
\text { Finger in } 1 / 2 \mathrm{~m} \\
\text { wegen Staar }\end{array}$ & $\begin{array}{l}\text { Nach dem ersten Aus- } \\
\text { setzen des.HgRecidiv, } \\
\text { das auf mehr Hg zu- } \\
\text { rückging }\end{array}$ \\
\hline $\begin{array}{l}2 \times 3 \mathrm{~g} H g \text { pro die. Wie } \\
\text { lange? }\end{array}$ & 6 Wochen & $\begin{array}{c}\text { Geheilt. } \\
\text { Finger in } 3 /{ }^{\circ} \mathrm{m} \\
\text { wegen Staar }\end{array}$ & $\begin{array}{l}\text { Nach } 14 \text { Tagen Status } \\
\text { idem }\end{array}$ \\
\hline $\begin{array}{l}4 \mathrm{~g} \text { Hg pro die } 24 \text { Tage hin- } \\
\text { durch. }-84 \mathrm{~g} \text { Ung. cin. }\end{array}$ & $\begin{array}{c}\text { Nach } \\
25 \text { Tagen }\end{array}$ & $\begin{array}{l}\text { Resectio op- } \\
\text { tico-ciliaris } \\
\text { wegen Phthisis } \\
\text { dolorosa }\end{array}$ & \\
\hline $\begin{array}{l}\text { Abtragung des Prolapses, } \\
3 \mathrm{~g} \text { Hg pro die. Nach } 6 \\
\text { Tagen wegen Diarrhoe aus- } \\
\text { gesetzt; Salicyl, Schwitzen. } \\
\text { Nach } 8 \text { Wochen wieder } \mathrm{Hg} \\
2 \mathrm{~g} \text {. Sublimatinjectionen } \\
\text { subconjunctival. }-44 \mathrm{~g} \\
\text { Ung. cin. }\end{array}$ & 10 Wach & $\begin{array}{c}\text { Resectio } \\
\text { optico-ciliaris } \\
\text { wegen Phthisis } \\
\text { incipiens }\end{array}$ & \\
\hline $\begin{array}{l}\text { Jeden zweiten Tag subcon- } \\
\text { junctivale Sublimatinjec- } \\
\text { tion. } 6 \mathrm{~g} \mathrm{Hg} \text { gro die, später } \\
4 \mathrm{~g}, \text { dann } 2 \mathrm{~g} .-144 \mathrm{~g} \\
\text { Ung. cin. }\end{array}$ & 7 Wochen & $\begin{array}{c}\text { Geheilt. } \\
\text { Finger in } 50 \mathrm{~cm} \\
\text { wegen Star }\end{array}$ & $\begin{array}{l}\text { Nach } 6 \text { Wochen S. } \\
1 / x 0, \text { Nachstaar }\end{array}$ \\
\hline $\begin{array}{l}\text { Suturen. } \mathrm{Hg} 6 \mathrm{~g} \text { für } 3 \text { Tage. } \\
\text { Nach } 6 \text { Tagen } 4 \mathrm{~g} \text {, später } \\
2 \text { und } 3 \mathrm{~g} \text {. Subconjunc- } \\
\text { tivale Sublimatinjectionen. } \\
-90 \mathrm{~g} \text { Ung. cin. }\end{array}$ & 8 Wach & $\begin{array}{c}\text { Resectico op - } \\
\text { tico-ciliaris } \\
\text { wegen Phthisis } \\
\text { dolorosa }\end{array}$ & $\begin{array}{l}\text { Die iritischen Erschei- } \\
\text { nungen wurden erst } \\
\text { nach } 8 \text { Tagen deutlich }\end{array}$ \\
\hline $\begin{array}{l}8 \mathrm{~g} \mathrm{Hg} \text { pro die. } \mathrm{Hg} \text { brjo- } \\
\text { datum intramuseulär, sub- } \\
\text { comjunctivale Sublimatin- } \\
\text { jectionen. - } 180 \mathrm{~g} \text { Ung. } \\
\text { cin. }\end{array}$ & $7 \stackrel{\text { Nach }}{\text { Wochen }}$ & $\begin{array}{l}\text { Resectio op- } \\
\text { tico-ciliaris } \\
\text { bei Phthisis in- } \\
\text { cipiens }\end{array}$ & $\begin{array}{l}\text { Nach } 4 \text { Wochen Bubus } \\
\text { reizlos; Granulationen } \\
\text { verschwunden }\end{array}$ \\
\hline
\end{tabular}




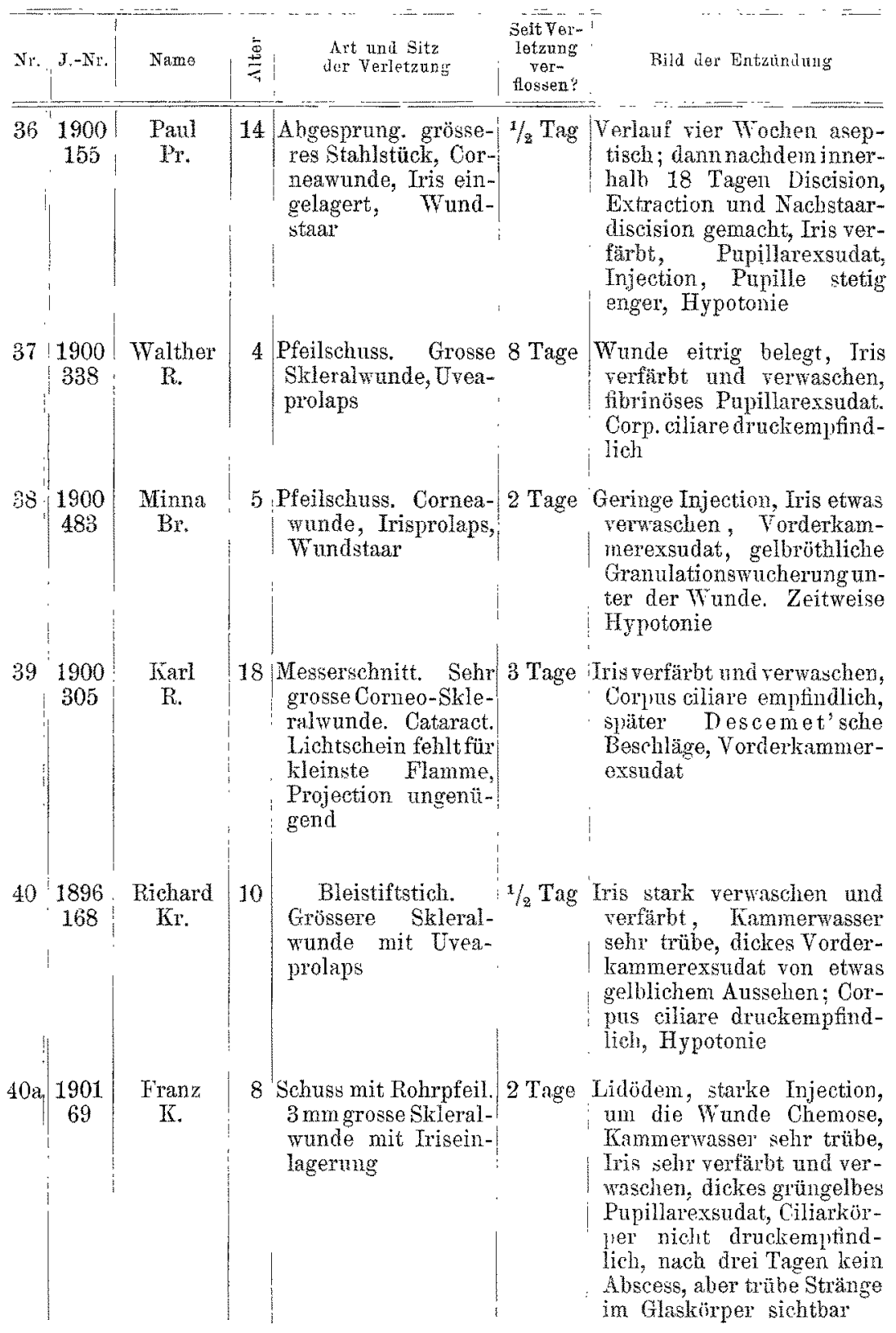

Während ich die Therapie dieser Gruppe von Entzündungen gemeinsam mit den eitrigen Uveitiden besprechen kann, seien zunächst einige Bemerkungen über die Diagnose eingefügt.

Hier erhebt sich zuerst die Frage: Stellt die Uveitis fibri- 
Zur Diagnose, Prognose u. Therapie d. perforir., infieirten Augapfelverletzungen. 17

\begin{tabular}{|c|c|c|c|}
\hline $\begin{array}{l}\text { Behandlungsweive. } \\
\text { (Selbstredend tiberall Atropin, } \\
\text { Verband, Bettruhe) }\end{array}$ & $\begin{array}{l}\text { Daner } \\
\text { der Behandlung }\end{array}$ & Pesultat & Bemerkingen \\
\hline $\begin{array}{l}\text { Nach Auftreten der iritischen } \\
\text { Erscheinungen } 3 \mathrm{~g} \mathrm{Hg} \text { pro } \\
\text { die. - } 72 \mathrm{~g} \text { Ung. cin. }\end{array}$ & 11 Wochen & $\begin{array}{c}\text { GeJeilt. } \\
\text { Finger in } 2 \mathrm{~m} . \\
\text { Nach } 1 / 2 \mathrm{Jah} \\
\text { Discision. }=1 / 10\end{array}$ & $\begin{array}{l}\text { Operationsinfection? } \\
\text { oder ist Entzündung } \\
\text { durch gehäufte Ein- } \\
\text { griffe manifest ge- } \\
\text { worden? }\end{array}$ \\
\hline $\begin{array}{l}\text { Wunde ausgebrannt, }{ }^{3 / 4} \mathrm{~g} \\
\mathrm{Hg} \text { rro die, subconjuncti- } \\
\text { vale Sublimatinjectionen }\end{array}$ & $\begin{array}{l}\text { Nach } \\
4 \text { Tagen }\end{array}$ & $\begin{array}{l}\text { Enucleation } \\
\text { wegen Fort- } \\
\text { schreiten der } \\
\text { Entzindung }\end{array}$ & $\begin{array}{l}\text { Die Section ergieht } \\
\text { Vereiterung des yor- } \\
\text { deren Glaskörperab- } \\
\text { sehnittes }\end{array}$ \\
\hline $\begin{array}{l}\text { Prolaps abgetragen, subcon- } \\
\text { junctival Sublimat und } \\
\text { Kochsalzinjectionen. } 3 / 4 \mathrm{~g} \\
\mathrm{Hg} \text { pro die. }-45 \mathrm{~g} \text { Ung. } \\
\text { cin. }\end{array}$ & 10 Wochen & $\begin{array}{c}\text { Geheilt. } \\
\text { V. }=\frac{1}{\infty} \text { wegen } \\
\text { Staar. Granu- } \\
\text { lationen resorbirt }\end{array}$ & \\
\hline $\begin{array}{l}\mathrm{Hg} \text { subconjunctival, } \mathrm{Hg} 2 \times \\
4 \mathrm{~g} \text { pro die } 8 \text { Tage hindurch, } \\
\text { dann } 4 \mathrm{~g} \text { pro die. }-240 \mathrm{~g} \\
\text { Ung, cin. }\end{array}$ & 11 Wochen & \begin{tabular}{|} 
Geheilt. \\
Finger in $30 \mathrm{~cm}$. \\
Nach 2 Monaten \\
Iridektomie. \\
S. nicht ge- \\
bessert wegen \\
starker Medien- \\
trubung
\end{tabular} & $\begin{array}{l}\text { Hg zu früh ausgesetzt, } \\
\text { Recidiv durch mehr } \\
\text { Hg geheilt }\end{array}$ \\
\hline $\begin{array}{l}\text { Prolajs abgetragen; } 2 \times 3 \mathrm{~g} \\
\text { Hg, Kanmerpunctionen u. } \\
\text { subconjunctivale Kochsalz- } \\
\text { injectionen. }-76 \mathrm{~g} \text { Ung. } \\
\text { ein. }\end{array}$ & 4. Wochen & Enucleation & $\begin{array}{l}\text { Die Section ergiebt } \\
\text { hinter der Skleral- } \\
\text { wunde einen circum- } \\
\text { scripten Glaskörper- } \\
\text { abscess }\end{array}$ \\
\hline $\begin{array}{l}\mathrm{Hg} \text { subeutan, } 4 \mathrm{~g} \text { Ung. cin. } \\
\text { neben subconjunctiv, Sub- } \\
\text { Iimat täglich, später Koch- } \\
\text { salz. Nach } 14 \text { Tagen } \\
\text { Jodlalium, Schwitzen. - } \\
54 \mathrm{~g} \text { Ung. cin. }\end{array}$ & 4 Wochen & $\begin{array}{c}\text { Geheilt. } \\
\text { S. } \text { K }^{1} / s^{-} \\
\text {Noch leichte } \\
\text { Stränge im Glas- } \\
\text { korper }\end{array}$ & \\
\hline
\end{tabular}

nos: nach perforixenden Verletzungen ein einheitliches Krankheitsbild dar. Diese Frage muss ich nach dem mir vorliegenden Material entschieden verneinen. Verstehen wir unter Uveitis fibrirosa eine Entzündung des gesammten oder einzeher Theile des

v. Graefe's Arckiv für Ophthalmologie. LIII. 1. 
Uvealtracts, bei welcher neben den entzindlichen Veränderungen der Tris eine rein fibrinöse Exsudation in der Vorder- und Hinterkammer im Vordergrunde des Krankheitsbildes steht, während von Eiterproduction klinisch absolut nichts wahrnehmbar ist, so komme ich dazu folgende zwei Gruppen zu unterscheiden:

1. Die wirklich rein fibrinösen Uveitiden, bei welchen Iris und Ciliarkörper mehr oder weniger reichlich fibrinöses Exsudat produciren, während an der Aderhaut nur kleinzellige, meist herdweise auftretende Infiltration, aber keine Exsudation oder Schwartenbildung nachweisbar ist, und

2. die Uveitiden, bei welchen die klinische Untersuchung ebenfalls lediglich eine fibrinöse Iritis oder Iridocyclitis nachweist, während der Hauptherd der Entzündung ein Glaskörperabscess ist, den das fibrinöse Exsudat in der Vorderkammer der Diagnose unzugänglich macht.

Wie häufig die eine, wie häufig die andere Form vorkommt, vermag ich natïrlich nicht zu sagen, da ich nicht sicher weiss, zu welcher Gruppe die geheilten Entzündungen ${ }^{1}$ ) zu rechnen sind. Für die enucleirten Fälle aber konute ich durch die Section der Bullbi feststellen, dass von fünf Augen nur eins durch rein fibrinöse Entzuindung verloren gegangen war (von fünf enucleirten Augen vor der Zeit, wo ich Quecksilber anwandte, nur zwei). In allen anderen wir die Verletzung bis in den Glaskörper gedrungen und hatte lier eine meist ziemlich circumscripte Eiterung eizeugt.

$\mathrm{E}_{\mathrm{s}}$ ist nun a priori nicht wahrscheinlich, dass eine Abscedirung iil. Glaskörper, selbst wenn sie nicht der directen Inspection zugänglich ist, ganz ohne Einfluss auf das Krankheitsbild sein sollte. Es ist anzunehmen, dass die Stoffwechselprodncte der im Glaskörper befindlichen Bakterien durch Diffusion auch in den vorderen Bulbusa:bschnitt gelangen und greifbare Veränderungen hervorrufen, die trotz der hier selbständig bestehenden flbrimösen Iritis diagnosticirbar sind. So sehen wir ja bei den reinen, metastatisch entstandenen Eiterungen in hinteren Bulbusabschnitt gar nicht selten Iritis mit Hypopyonbildung auftreten, die zweifellos als eine Ptomainwirkung

1) Selbstredend zehören diese Falle eigentlich in die Grupe der puruIenten Uveitiden. Wenn ich sio trotzdem hier unter den fbrinösen Entzündungen anfgeführt habe, so geschah dies, weil bisher eine exacte Diagnose dieser unsichtbaren Abscesse noch nicht möglich ist, und weil ich versuchen will, durch Vergleich mit den rein fibrinösen Uveitiden zur dufstellung differential-diagnro-tischer Merkmale zu gelangen. 
Zur Diagnose, Prognose u. Therapie d. perforir., innicirten Augapfelverletzungen. 19

aufzufassen ist. So beschreibt auch Strauby $^{\mathbf{y}}$ in seinen Fällen von schwerer und mittelschwerer Hyalitis, bei welchen der Sitz der Infectionserreger auch nur im Glaskörper zu suchen ist, Iritis mit Synechienbildung und Hypopyonbildung. Die Fälle mit Hypopyonbildung sollen hier aber nicht berücksichtigt werden; ich habe sie der dritten Gruppe, den eitrigen Uveitiden zugezählt; sie bieten im Allgemeinen der Diagnose weniger Schwierigkeiten. Vielmehr wäre es wünschenswerth, gerade bei den scheinbar rein fibrinösen Entzündungen einen unsichtbaren Glaskörperabscess klinisch diagnosticiren zu können, da derselbe für die Prognose von der übelsten Bedeutung ist.

Durchmustere ich hierauf das mir vorliegende Material, indem ich annehme, dass die geheilten Fälle, bei welchen sich spätestens sechs Wochen nach der Verletzung der Glaskörper völlig klar fand, sicher keine Eiterung in demselben gehabt hatten, so gelange ich zu folgendem Resultat:

Die Diagnose anf unsichtbaren Glaskörperabscess lässt sich bei Iritis oder Iridocyclitis fibrinosa in einer Reihe von Fällen mit ziemlicher Sicherheit stellen, während in anderen kein Symptom auf diese schwere Complication hindeutet. Das sicherste Kennzeichen ist ein schon in den ersten Tagen auftretendes, dichtes, graues Exsudat in der Vorderkammer, das Iris und Pupille gleichmässig überzieht. Bei der rein fibrinösen Ureitis entwickeln sich diese Vorderkammerexsudate im Allgemeinen viel langsamer und erreichen meist nicht annähernd eine solche Dichtigkeit und Masse. Hand in Hand mit diesem acuteren Einsetzen der Entzündung geht gewöhnlich Druckempfindlichkeit des Corpus ciliare, die bei den rein fibrinösen Entzündungen, abgesehen von der Wundgegend, in den ersten 8 bis 14 Tagen zu fehlen pflegt und erst später sich einstellt; sie bildet damn für viele Autoren das wohlbekannte Signal zur Entfernung des Augapfels.

Gar keine Anhaltepunkte giebt uns das Aussehen der Wundränder, die nicht häufiger und nicht stärker infiltrirt sind, wie bei. den fibrinösen Entzündungen. Und auch das zeitweise Auftreten von etwas Lidödem und von leichter Chemose ist nicht von wesentlicher Bedeutung, da es auch bei den rein fibrinösen Entzündungen, zumal nach Prolapsabtragung, Wundnaht und dergleichen, auf-

1) Straub, Zur Klinik der Hyalitis. IX. internationaler Ophthalmologencongress zu Utrecht. S. 408. 1899. 
treten kann. Immerhin wird ihr Vorhandensein, zumal wenn es sich um stärkere Grade handelt, den Verdacht auf Glaskörpereiterung stützen,

Keine so sehr grosse Bedeutung vermag ich der Functionsprüfung zuzuerkennen. Man sollte erwarten, dass sich ein Glaskörperabscess durch Störung des Projectionsvermögens bald verrathe. In der That ist dies jedoch nur in den vorgerückteren. Stadien der Fall - kurz vor der Enucleation war die Projection, mit Ausnahme von Fall 43 , immer ungenügend -; in den frühen Stadien aber, so lange der Abscess noch klein ist, lässt dies Symptom oft im Stich. Erstens fand ich die Projection nicht seiten noch acht und zeln Tage wach der Verletzung ungestört, und in den geheilten Fällen von Abscess blieb sie stets richtig; dann aber kommen Anomalien der Projection auch ohne Abscessbildung zuweilen vor, sei es durch die mechanischen Folgen des Tranmas, z. B. Glaskörperblutung oder Netzhautablösung, sei es in Folge voribergehender Schädigung, deren Griinde noch nicht teststehen (Toxinwirkung?). Ich konnte mehrmals bei rein fibrinöser Uveitis, die sicher nicht mit Abscess combinirt war, und wo auch alle Anhaltspunkte fuir eine Glaskörperblutung fehlten, Fehlen der Projection nach einer oder mehreren Richtungen nachweisen, während mit dem Rückgang der entzündlichen Erscheinungen die Projection wieder richtig wurde, sich eventuell sogar Sehvermögen wieder lierstellte. So war es z. B. in den Fällen $33^{1}$ ) und 39. Sonach stellt die mangelhafte Projection beim Glaskörperabscess ein erst in späteren Stadien auftretendes Symptom dar, das zur Frühdiagnose nicht zu verwerthen ist.

Grosses Gewicht muss schliesslich auf die exacte Feststellung der Lage und der Tiefe der Wunde gelegt werden, speciell auf die Frage, ob sie bis in den Glaskörper reicht. In allen Fällen, die zur Enucleation kamen, konnte ich anatomisch eine directe Verletzung des Corpus vitrewu nachweisen, und auch in den geheilten Fällen war nach Art und Lage der Wunde das Gleiche anzunehmen. Es scheint demnach, dass eine Propagation von Eiterbakterien aus der Iris oder der vorderen Kammer in den hinteren Bulbusabschnitt, wenn überhanpt, doch nur sehr selten statt hat, und dass es sich bei der Abscessbildung stets um eine directe Infection des Glaskörpers handelt.

Als Beispiele, wie verschieden die klinischen Symptome beim

1) Conf. S. 38. 
Zur Diagnose, Prognose u. Therapie d, perforir., inficirten Augapfelverletzungen. 21

Glaskörperabscess sein können, mögen folgende drei Fälle hier beschrieben sein:

Fall 5 der Tabelle: Der 6jährige Knabe Paul T. wurde am 18. VIII. 1895 mit einem Flitzbogenpfeil ins linke Auge geschossen. Das Sehvermögen erlosch sofort, auch klagte der Knabe tiber heftige Schmerzen.

Am nächsten Tage fand sich links leichte Schwellung und Röthung der Lider und starke ciliare Injection, keine Chemose. In der Cornea eine 2-3 mm lange, zipflige Wunde, in der die Iris liegt; die Wundränder sind nicht infiltrirt. Die Vorderkammer ist seicht, das Kammerwasser trube, die Iris stark verwaschen und verfäbt. Auf ihr und auf dem Pupillargebiet liegt iiberall eine dicke gravliche Exsudatschicht. Corpus ciliare leicht druckempfindlich. Lichtschein fehlt für niedrigste Flamme; Projection unsicher. Prolaps abgetragen, eine Hornhautsutur; subconjunctivale Sublimatinjection $(1 / 10 \mathrm{cem}$ einer Lösung $1: 1000), 4 \mathrm{~g}$ Ung. cin., Atropin, feuchter Verband, Bettruhe.

Am folgenden Tage sind die Lider nicht stärker geschwollen, unten ist, jedenfalls als Folge der Sublimatinjection, Chemose aufgetreten; das Vorderkammerexsudat noch dicker. Ther. eadem.

Tags darauf hat das Exsudat noch mehr zugenommen, und auch das Lidödem und die Chemose sind etwas stärker. Es wird daher zur Enucleation geschritten. - Die Section des Bulbus ergiebt ein sehr dichtes, fibrinöses Exsudat der Vorderkammer, von reichlichen Eiterzellen durchsetzt, und einen grösseren Abscess in vorderen Glaskörperabschnitt. Die Verletzung war bis in den Glaskörper gedrungen.

Fall 25 der Tabelle: Dem 17jährigen Schmiedelelurling Max Ki. flog am 16. XII. 1898 ein Stahlsplitter ins rechte Auge; das Sehvermögen sank selrr schnell; unberteutende Schmerzen. Am folgenden Tage fand ich unten aussen eine $8 \mathrm{~mm}$ lange Corneo-Skleralwunde, deren Ränder kaum infiltrint sind; etwas Glaskörpervorfall. Die ganze Vorderkammer ist voll Blut. Bulbus weich und sehr druekempfindlich. Geringe eiliare Injection, eine Spur Lidödem, keine spontanen Schmerzen. Das Sideroskop ergiebt unten aussen den grössten Ausschlag; Lichtsehein und Projection sind gut. Mit dem Hirschberg'schen Magnet wird durch die Wunde ein unregelmässig gestalteter, 1,5 mm langer Eisensplitter extrahirt. Wunde liegt gut. Atropin, Verband, Bettrube, $2 \times 4 \mathrm{~g}$ Ung. cin. pro die.

In den nächsten Tagen stellen sich $a b$ und an geringe Schmerzen ein, das Blut aus der Vorderkammer beginnt sich zu resorbiren und lässt eine stark verfärbte und verwaschene Iris zum Vorschein kommen.

Etwas Chemose, die aber wohl grösstentheils durch regelmässige subconjunctivale Sublimatinjectionen bedingt ist. Vier Tage später zeigt sich iiber dem Hyphaema ein grauer Exsudatstreif in der Vorderkammer, der in den nächsten Tagen sich etwas verbreitert; das Blut resorbirt sich sehr langsam, die Wunde schliesst sich.

Acht Tage nach der Operation ist der Zustand ziemlich unverändert. Täglich neben den Einreibungen eine Sublimatinjection unter die Bindehaut and zugleich Punction der Vorderkammer. Hierbei tritt zunächst Besserung 
ein; the spoutanen Schmerzen werden geringer, die Iris nimmt ein besseres Aussehen an, und das Exsudat zieht sich in sich zusammen.

Die Besserung lält etwa fünf Tage an, dam nimmt lie Trübung des Kammerwassers und he Verfärbang der Iris wieder $z a$, der intraoculare Druck sinkt, und die Projection wird nacl oben - die Wunde lag unten ungenügend. Deshalb, 21/2 Wochen nach dej" Magnetextraction, Enueleatio brilbi. - Die Section ergiebt einen mittelgrossen Glaskömerabscess.

Fall 40 der Tabelle: Der 10 juhrige Richard Kr. wurde an 1. VII. 1896 mit einem Bleistift ins linke Auge gestochen. Am gleichen Abend thndet sich las Ange nur wenig injicirt; nahe der äusseren Corneagrenze in der Sklera eine verticale Wunde, aus der mit Fibrin bedeckte Cventheile prolabirt sind. Kammerwasser trübe, Iris etwas lyperímisch, im Pupillargebiet ein zartes, graues Exsudat. Reichliel dropin, feuchter Verband. Am folgenten Morgen ist die Pupille etwas erweitert; der Prolaps wird abgetragen, das Kammerwasser abgelassen. $2 \times 3 \mathrm{~g}$ Uag. ein.

Am nächsten Morgen ist die Iris sehr stark verwaschen and Ferfärbt, die Trubung des Kammerwassers hat zugenommen, das Exsudat ist riel dicker geworden und lat einen etwas gelblichen Schein; auf der Wunde liegt eitrig aussehender Belag. Starke Injection, Ciliarköper druckempfindlich. Mit dem Galvanokanter wird die Wunde energisel ausgebrannt, die Vorderkammer eroffnet and das Exsudat in toto heransgezogen. Zu der übrigen Therapie treten tägliche Punctionen der Kammer und subconjunctivale Koclisalzinjectionen.

Hierbei tritt in den nächsten acht Tagen ganz wesentliche Besserung ein. Die Injection nahm ab, die Wunde remarbte, die Iris bekam ein besseres Aussehen und die Pupille erweiterte sich; der Drucksehmerz verlor sich almählich, und das Kammerwasser wurde Klarex. Nur das Pupillargebief ist beständig von einem dicken Exsudat eingenommen. Wähend diese Besserung der initischen Erscheinungen anhielt, trat in der folgenden Woche zunehmende Hypotonie auf, die Cornea fing an, sich zu verkleinern, die Kammer wurde seicht, Lichtschein und Projection ungentigend, und die Injection wnd Lichtschen nahmen zu, so dass id mich am 27. VII. zur Enucleation entselliessen musste. - Die Section ergab in der Nähe der Skleralwunde eine circumscripte eitrige Infiltration des Glaskörpers.

Von diesen Beobachtungen zeigt nux die erste einen sturmischen Verlaut, wie man ihn bei einer intraocularen Eiterung erwarten zu kümen glaubt. Bereits am Tage nach der Verletzung findet man hier starke Veränderungen an der Iris, ein dickes Pupillarexsudat, das den Einblick in den Glaskörper unnöglich macht, starke ciliare Injection und Druckemptindlichkeit. Lnd die Erscheinungen steigen sich so schnell, dass bereits nach drei Tagen die Enucleation nöthig wird. Im zweiten Falle hingegen dauerte es vier Tage, bis reichlichere Exsudation auftrat, deren Nachweis allerdings durch das grosse Hyphaema sehr erschwert wurde. Dieselhe nahm durchaus nicht rapide zu, in Gegentheil führte die Therapie nach acht Tagen noch- 
Zur Diagnose, Prognose n. Therapie d. perforir, inficirten Augapfelverletzungen. 23

mals eine deutliche Besserung im vorderen Bulbusabschnitt herbei, bis dann die schon nach zwei Wochen einsetzende Plathise das Signal zur Enucleation gab. Da die leichte Chemose ganz wohl durch die Sublimatinjectionen bedingt sein konnte, fehlten bis zum frühzeitigen Auftreten der Hypotonie alle bestimmteren Anzeichen für den Glaskörperabscess. Und auch der dritte Fall, bei dem schon nach einem Tage ein reichliches Vorderkammerexsudat und Ciliardruckschmerz sich zeigte, wies unter dem Einfluss der Therapie eine erhebliche Besserting der Tritis auf. Auch hier war es die schon nach $2 \frac{1}{2}$ Wochen beginnende Phthise, die zur Enucleation nöthigte.

Im Gegensatz zu den eben beschriebenen Fällen, die im Allgemeinen mehr den Namen einer subacuten Entzündung verdienen, verlaufen die rein fibrinösen Uveitiden in der Regel viel chronischer. Fs dauert meist mebrere Tage, einmal sogar acht Tage (Eall 34), bis die entzündlichen Veränderungen eine solche Höhe erreicht haben, dass über die erfolgte Infection des Auges kein Zweifel mehr bestehen kann. Die Verfärbung und Verwaschenheit der Iris bleibt geringfügiger, und vor Allem die Exsudatbildung in der Vorderkammer erreicht niemals eine solche Ausdehnung und Dichtigkeit, wie bei gleichzeitiger Existenz eines Abscesses im Glaskörper. Gewöhnlich handelt es sich sogar nur um die Bildung mehr oder weniger dichter Membranen im Pupillargebiet und um die Ausbildung himterer Synechien.

Diesen scheinbar geringfügigeren Veränderungen entspricht aber, wie bekannt, durchaus nicht ein gutartiger Verlauf. Wie schon das Auftreten sympathischer Entzündung beweist, zu der ja gerade diese Fälle besonders disponiren, wohnt den Krankheitserregern eine grosse Propagationsfähigkeit inne. Sie wandern bald aus der Iris in den Ciliarkörper, und die Cyclitis kann dann zur Phthisis bulbi führen.

Es ist deshalb die Betheiligung des Ciliarkörpers an der Entzindung prognostisch von ungünstiger Bedeutung und ihre Diagnose von Wichtigkeit. Geringere Grade dieser Cyclitis werden "uns zweifellos in der Regel entgehen, da ihre Symptome im Krankheitsbilde der Tritis aufgehen. Für die höheren Grade halte ich folgende drei Anzeichen für charakteristisch: Druckschmerz, Descemet'sche Beschläge und Hypotonje. Von den sonstigen Anzeichen der Oyclitis sind Glaskörpertribungen wegen des Pupillarexsudates wohl nur ausnahmsweise diagnosticirbar, die speckigen Excrescenzen aus dem Kammerwinkel, die sich besonders bei den scrophulösen und tuberculösen Trido-Cyclitiden nicht selten finden, habe ich bei dieser trau- 
matischen Form niemals gesehen, und das Oedem des oberen Lides; das Fuchs für die acute Oyclitis als charakteristisch auführt (Lehrbuch, 4. Aufl., 1894, S. 310), findet sich zu hänfig als einfache Folge der Verletzung, als dass man darauf besonderen Werth legen könnte.

Descemet'sche Beschläge scheinen recht selten zu sein, jedenfalls viel seltener, als bei der sympathischen Entzindung; icl habe sie nux ein einziges $\mathrm{Mal}$ gesehen ( $\mathrm{Fall}$ 39). Es handelte sich hier um einen sehr chronisch verlanfenden Fall mit geringen entzündlichen Erscheinungen, bei dem acht Wochen nach der Verletzung eine mässige Anzahl Beschläge auftrat. Der Endausgang war schliesslich günstig.

Ciliardruckschmerz, natirlich abgeseben von dem leichten Wundschmerz, der in den ersten Tagen in der Wundgegend ganz gewöhnlich rorhanden ist, finde ich unter den 39 Fällen elf Mal notirt. Darunter befinden sich die rier enucleirten Bulbi mit Glaskörperabscess $(5,25,27,37)$, sechs Bulbi wurden schliesslich phthisisch und mussten bis auf einen, der wieder völlig reizlos wurcle, theils enucleirt, theils resecirt werden $(9,17,21,22,31,34)$, und nur einmal (Fall 33) gelang es, den Bulbus mit leidlicher Sehschärfe $(\mathrm{S} .=1 / 10)$ zu erhalten. Doch war hier die Einpfindlichkeit nur in den ersten Tagen nach dem Trauma und auch nur in der unteren Hälfte des Ciliarkörpers nachweisbar, wo die Wunde sich befand, so dass es sich vielleicht nur um einen besonders ausgebreiteten Wundschmelz gehandelt hat.

Diese Darlegungen beweisen, dass ausgesprochene Druckempfindlichkeit des Ciliarkörpers, die nicht nur in den ersten Tagen nach der Verletzung und nicht nur in der Uingebung der Wunde auftrit, von sehr ungünstiger prognostischer Bedeutung ist, aber die Möglichkeit einer Heilung doch nicht völlig ausschliesst (vgl. z. B. auch den Fall von Samelsohn ${ }^{1}$, wo $\mathrm{S} .={ }^{1 / 2}$ wieder erlangt wurde).

Ebenfalls von ubler Vorbedeutung ist das Sinken des intraocularen Druckes, wenn es bei schon völig geschlossener Wunde auftritt. Es ist dies meist der Anfang der Phthisis bulbi. Doch ist es auch möglich, dass der Druck sich nach einiger Zeit wieder normalisirt, keine Netzhautablösung eintritt, und das Auge schliesslich doch noch ein Ieidliches Sehvermögen erlangt. Unter den oben angeführten 37 Fällen habe ich dies Verhalten vier Mal beobachtet

1) Samelsohn, Zur Nosologie und Therapie der sympathischen Erhankungen. Arch. f. Augenheilk. IV. 2. S. 280, 1874. 
Zur Diagnose, Prognose u. Therapie d. perforir., inficirten Augapfelverletzungen. 25

(Eall $30,33,36$ und 38 der Tabelle), und aus der Literatur über sympathische Entzindung ist mir noch eine nicht unerhebliche Anzahl weiterer solcher Fälle bekannt.

Tritt diese Hypotonie ein, während das Auge sich noch unter Verband befindet, so habe ich auf völlige Beseitigung jedes von aussen wirkenden Druckes Gewicht gelegt, und wo es noch nicht möglich schien, das Ange ganz frei zu lassen, es unter einen Hohlverband mit gewölbter Aluminiumplatte (von Snellen angegeben) gelegt; wie ich glaube, mit gutem Erfolg.

Schliesslich möchte ich noch eine Erscheinung erwähnen, die bei traumatischer Irido-Cyclitis sehr selten vorzukommen scheint, wenigstens in der Titeratur nirgends erwähnt wird, die aber in drei der obigen 37 Fälle in höchst auffallender Weise sich zeigte; das ist das Aufschiessen gelbröthlicher Knötchen aus der Iris, ähnlich Condylomen oder Tuberkelknötchen. Die drei Fälle sind folgende:

Fall 33 der Tabelle: Der 15 jährige Schlosserlehrling Paul B. wurde am 20. X. 1899 mit einer Seheere ins linke Auge gestochen. Bei der Vorstellung am 22. X. findet sich leichtes Oedem des oberen Lides, leichte Chenose bei mässiger Injection; in der unteren Hornhauthälfte eine ca. $7 \mathrm{~mm}$ lange Wunde mit etwas gequollenen Rändern und Iriseinlagerung; die obere Hälfte der Iris stark verwaschen und verfärbt; in der Vorderkammer ein ausgedehntes, grauliches Exsudat, das nicht sicher erkennen lässt, ob Wundstaar vorliegt. Untere Hälfte des Ciliarkörpers leicht druckempfindlich; Funetionen wegen Lichtschen nicht zu bestimmen. Therapie: jeden zweiten Tag eine subconjunctivale Sublimatinjection, zwei Theilstriche einer Lösung 1:2000, 6 g Ung. cin. täglich, zwei Mal wöchentlich Schwitzen, reichlich Atropin, feuchter Verband, Bettruhe.

Im Laufe der nächsten aclit Tage blasst das Auge allmählich ab, die Sehmerzhaftigkeit versclıwindet, das Aussehen der Iris wird besser und das Exsudat resorbirt sich grösstentheils, so dass ein Wundstaar sichtbar wird; Lichtschein fehlt für kleinste Flamme; Projection nach oben und nasenwärts ungenủgend (Glaskörperabscess?).

Vom 4. XI. ab werden anstatt der Sublimat- Kochsalzinjectionen gemacht und vom 15. XI. ab mit Aluminiumplatte verbunden, da der Druck etwas niedrig ist. Am 18. XI. bemerkt man hinter der Corneawunde eine Anzahl gelbröthlicher, etwa stecknadelkopfgrosser Knötchen, die dicht an einander gedrängt aus dem Pupillartheil der Iris hervorspriessen und bis zur Hornhautrückfläche reichen; mit der Lope sind zahireiche Gefässe in ihnen deutlich zu erkennen. Ibre Entwicklung geht in wenigen Tagen vor sich, und schon nach acht 'Tagen ist deutlich eine langsame Verkleinerung derselben zu constatiren.

Inzwischen haben sich die entzündlichen Erscheinungen stetig weiter zurüekgebildet, so dass vom 20 . XI. ab nur noch $2 \mathrm{~g}$ täglich gerieben 
und vom 28.XI. ah ganz mit den Inunctionen antgehört wurde. Am 9. XII. wird Patient mit Atropin-Cocainsalbe entlassen; die gelben Krnötchen sind noch nicht ganz resorbirt; Druck normal; Fingerzählen in $50 \mathrm{~cm}$.

Am 24. I. 1900 ist von den Knötehen vichts mehr zu entclecken, das Auge ist blase und reizlos, die Staarmassen grösstentheils resorbirt. Wit $+13 \mathrm{D} \mathrm{S}_{0}=1 / 10$. Weitere Besserung zu enwarten.

Fall 35 der Tabelle: Der 16 jallige Hofganger Karl R. staeh sich am 14. II. 1900 beim Rübenstechen mit dem Vesser ins rechte Auge. Nachdem er vier Tage mit Umsehlagen behandel war, fand sich am 18. II. tolgender Befund: Ange mässig lichtsehen, stakke ciliare Injection, perforirende Wmde durch die ganze Conea von oben bis unten, der die ris anliegt. Iris stark verwaschen und verfäbt; Wundstaar. Lichtsehein und Projection gut. Therapie: $2 \Varangle t g$ Ung. cin. unreiben, Injection ron Hydrargyrum bijodatum in die Glutäen, jeden zweiten Tag eine subconinetivale Sublimatinjection, viel Atropin, feuchter. Verband, Bettruhe.

Hierhei ging in den nächsten Wohen die Injection zurück, und das Aussehen der Iris wurle besser, Schmerzen waren nio rorbanden; die Pupille aber hieb stets eng, von zartem Exsudat ansgefult, die Kammer seicht, und ein unässiger Reizzustand wolle nicht verschwinden. Bei diesem Zustande des Auges traten an 20. III. goldgelb aussehende, reichlich vascularisirte Knötthen hinter der inzwischen verheilten Hornhantnarbe in der Iris auf, die zu mehreren neben einander liegend fast die Hophautrückfäche erreichen. Die Functionen sind noch gut.

Nun aber wird der Zustand stetig schlechter, die Injection stärkel, die Pupille ganz eng, die Funetionen ungenügend, der Drkck weich; die yelben Knötchea nehmen an Ausdelnung noch etwas zu. Deshalb am 7.IV. lie Resectio optico-ciliaris. Nach acht Tagen Entiassuns. - - 31/2 Wochen später ist das Auge reizfrei, kaum noch injicirt, die Phthisis wenig fortgeschritten, die gelblichen Knötchen ganz rerschwunden.

Fall 38 der Tabelle: Die 5jährige Minna Br. wurde ror zwei Tagen wit einem Pfell ins redite Auge gesehossen. Es fand sich bei geringer Cilianinection eine grosse Hornhautwunde, aus welcher die Iris vorgefallen ist, Pupille selr eng, Kammer aufgehohen. Keine deutliche Verwaschenheit der Iris. Therapie: Reinigung, Atropin-Sublimatsalbe, Ver. iand, Bettuhe.

Am folgenden Tage ist die Pupille etwas weiter, man kann einen Wundstaar erkennen, aber die Iris sielt etwas verwaschen aus. Deshalb uach Abtragung des Prolanses eine subconjunetivale Sublimatinjection jeden zweiten Tag, and $" / 4 \mathrm{~g}$ Ung. cin. täglich einreiben. Hierbei tritt, nachdem anfangs die iritischen Erseheinungen noch melrere Tage zugenommen hatten und ein leichtes Pupillarexsudat aufgeteten war, allmähliche Bessermg ein; las Auge wird blasser, die Iris sieht hesser ans. Vom 21. XII. ab statt ler Sublimatipjectionen regelmässige Kochsalzeinspritzungen.

Am 25. XII. bemerkt man röthliche Knötchen, die aus der Iris in ler Gegend der Corneawunde hervorspriessen und feine Gefäse in die getrübte Cornea senden. Nachdem sie melrere Tage an Zahl und Ansdelmung zugenommen haben, bleiben sie eine Zeit lang unverändert, beginnen aber schon am 7. I. 1901 abzublassen und sich zurïckzubilden. 
Zur Diagnose, Prognose u. Therapie d. perforir., inficirten Augapfely erletzungen. 27

Die Patientin darf jetzt täglich eine Stunde aufstehen. Ende dieses Monats ist der Druck eine Woche hindurch subnormal, hebt sich dann aber wieder und das Kind kam am 10. II. mit reizlosem Auge entlassen werden. Die Lichtempfindung ist prompt, Projection wegen der Jugend nicht zu prüfen; die röthlichen Knötchen sind völlig versehwunden.

Es traten also in diesen drei Fällen zu einer Zeit, wo die entziindlichen Erscheinungen schon im Riickgange waren, gelbliche bis röthliche Knötchen, zu dichten Haufen gedrängt, in der Iris auf. Sie waren nicht unregelmässig über deren Oberfläche zerstreut, wie man es bei Tuberkeln sieht, mit welchen sie sonst die grösste Aehnlichkeit hatten, sondern an die Umgebung der Hornbautnarbe gebunden, in welche sie in einem Falle feinste Gefässe entsandten; sie hatten folglich stets strichförmige Anordnung. Auf den Verlauf der Entzündung waren sie völlig ohne Einfluss, keine Exacerbation war mit ihrem Auftreten verbunden. Thre Rückbildung erfolgte im Laufe einer Reihe von Wochen ganz allmählich bis zur Restitutio ad integrum.

Ueber ihre Bedeutung ist es schwer, etwas Bestimmtes auszusizen. Thre Localisation in der Nähe der Hornhautuarbe macht es wahrscheinlich, dass sie nicht einfach als Product der Iritis, resp. der Erxeger dex Tritis aufzufassen sind, sondern mit dem Vernarbungsprocess in irgend welchem Zusammenhange stehen. Allerdings ist dann auffällig, dass sie erst so spät, nach drei bis vier Wochen, sich zeigen, wenn die Vernarbung im Wesentlichen vollendet ist.

Mehr Wahrscheinlichkeit hat roh! die Annahme, es habe sich um eine reactive Knötchenbildung um kleine Fremdkörper herum gehandelt, die bei der Verletzung ins Augenimnere gedrungen waren, etwa analog der Rupenhaariritis. Auch von letzterer wissen wir ja, dass die Knötchenbildung dem Eindringen der Haare erst nach längerer Zeit folgt. Auffällig wäre dann allerdings die schnelle Rückbildung der Könötchen.

So muss die Frage nach ihrer Bedeutung noch offen bleiben, bis vielleicht einmal eine anatomische Untersuchung nähere Anhaltspunkte liefert.

\section{Uveitis purulenta traumatica.}

Unter dem Namen "Uveitis purulenta traumatica“ fasse ich alle Fälle von traumatisch entstandener Entzündung des Augeninneren zusammen, bei welchen neben der fibrinösen Exsudation klinisch Eiterbildung in Vorderkammer oder Glaskörper diagnosticirt werden kann. 
Panophthalmie ist eine Unterabtheinng der Uveitis purulenta und umfasst die schwersten Fälle derselben, bei welchen es durch rapide Vermehrung der Eiterbalterien im Glaskörper zu so massenhatter Entwicklung von Umsatzproducten derselben kommt, dass ihre Diffusion in die retrobulbären Gewebe eine starke Schwellung derselben und dadurch Exophthalmus hervorruft. Eine Spontamperforation, die Fuchs (Lehrbuch, 7. Aufl, 1898, S. 379) fordert, halte ich durchaus nicht für nothwendig zur Sicherung dieser Diagnose. Ich habe dieselbe nur ausnahmsweise schon in den ersten Tagen auftreten sehen, fast stets kommen die Kranken mit noch upperforirtem Bulbus zu uns; und da wir gewohnt sind, bei eitriger Entzündung des ganzen Uvealtracts mit Protrusio bulbi sofort zu cnucleiren oder zu exenteriren, so

\begin{tabular}{|c|c|c|c|c|c|c|}
\hline Nr. & $J-N \pi x$ & Name & $\frac{\tilde{9}}{\frac{\pi}{4}}$ & $\begin{array}{l}\text { Art und Sitz } \\
\text { der Yerletzung }\end{array}$ & $\mid \begin{array}{c}\text { Suit Ver- } \\
\text { letzung } \\
\text { var- } \\
\text { flossen? }\end{array}$ & Bild der Entzüzudung \\
\hline 41 & $\begin{array}{c}1895 \\
258\end{array}$ & $\begin{array}{l}\text { Ferdinand } \\
\text { R. }\end{array}$ & 29 & $\begin{array}{l}\text { Rohr ins Auge ge- } \\
\text { stossen. Kleine } \\
\text { Hornhautwunde, in } \\
\text { der ein dunkles } \\
\text { Pünktchen sichtbar. } \\
\text { Functionen gut }\end{array}$ & 2 Tage & $\begin{array}{l}\text { Wunde eitriginfiltrirt, Eiter } \\
\text { an Cornearickfläche und } \\
\text { an Boden der Kammer. } \\
\text { Iris sehr stark verwaschen } \\
\text { und verfärbt, Yupillarex- } \\
\text { sudat; Ciliarkörper druck- } \\
\text { empfindlich. - Drei Wo- } \\
\text { chen später nach Heilung } \\
\text { der Eiterung Desce- } \\
\text { net'sche Beschläge }\end{array}$ \\
\hline 42 & $\begin{array}{l}1895 \\
239\end{array}$ & $\begin{array}{l}\text { Agnes } \\
\mathrm{S} .\end{array}$ & 2 & $\begin{array}{l}\text { Explosion einer } \\
\text { Platzpatrone. Sehr } \\
\text { grosse Corneo-Skle- } \\
\text { ralwunde mit Uvea- } \\
\text { prolaps }\end{array}$ & 1 Tag & $\begin{array}{l}\text { Chemose, Iris stark rex- } \\
\text { waschen und verfärbt, Ci- } \\
\text { liarkörper druckempfind- } \\
\text { lich. Kammer roll Blut } \\
\text { und eitrig-fibrinösem Fx- } \\
\text { sudat. Später Wundgegend } \\
\text { eitrig infltrirt }\end{array}$ \\
\hline 43 & $\begin{array}{l}1896 \\
398\end{array}$ & $\begin{array}{c}\text { Minna } \\
\mathrm{D} .\end{array}$ & 52 & $\begin{array}{l}\text { Nadelstich. Fleine } \\
\text { Skleralwunde mit } \\
\text { Glaskorperprolaps. } \\
\text { Functionen gut }\end{array}$ & 5 Tage: & $\begin{array}{l}\text { Lidödem, starke Injection, } \\
\text { Iris etwas verfärbt, ver- } \\
\text { waschen, Ciliarkörper sehr } \\
\text { druckempfindlich; Glas- } \\
\text { körperabseess }\end{array}$ \\
\hline 44 & $\begin{array}{c}1896 \\
71\end{array}$ & $\underset{\mathrm{K} .}{\operatorname{Emil}}$ & 16 & $\begin{array}{l}\text { Abgesprung. Bohrer. } \\
\text { Grosse Corneal- } \\
\text { wunde mit Tris- und } \\
\text { Glaskörperprolaps. } \\
\text { - Amaurose }\end{array}$ & 1 Tag & $\begin{array}{l}\text { Starke Injection, Chemose, } \\
\text { fibrinös-eitriges Exsudat } \\
\text { in Vorderkammer, Ciliar- } \\
\text { kiorper druckempfindlich }\end{array}$ \\
\hline 45 & $\begin{array}{l}1896 \\
245\end{array}$ & $\begin{array}{c}\text { Wilhelm } \\
\text { S. }\end{array}$ & 17 & $\begin{array}{l}\text { Abgesprung. Eisen- } \\
\text { splitter. } \\
\text { Hornhantwune } \\
\text { Wundstar. Func- } \\
\text { tionen gut }\end{array}$ & 2 Tage & $\begin{array}{l}\text { Ciliare Injection, flbrinoses } \\
\text { Exsudat an der Hornhaut } \\
\text { und auf der Linsenkapsel, } \\
\text { Iris verwaschen und ver- } \\
\text { färbt, Hypopyon; Corpus } \\
\text { ciliare nicht druckempfind- } \\
\text { lich }\end{array}$ \\
\hline
\end{tabular}


Zur Diagnose, Prognose u. Therapie d. perforir., inficirten Augapfelverletzungen. 29

würden wir nur höchst selten in die Lage kommen, eine Panophthalmie zu diagnosticiren, wenn die Spontanperforation dafür Vorbedingung wäre. Zuzugeben ist indess, dass bei längerem Zuwarten in den meisten dieser Fälle eine Perforation von innen her in der That eingetreten wäre.

In folgender Tabelle habe ich die in den letzten sechs Jahren hier behandelten Fälle von eitriger Entzündung eines oder mehrerer Theile des Uvealtracts zusammengestellt. Ausgeschlossen davon habe ich nur 16 Fälle von ausgesprochener Panophthalmie - nach obiger Definition -, bei welchen ich primär exenterirt, in einzelnen Fällen auch enucleirt habe. Ihre Mittheilung wäre ohne weiteres Interesse gewesen.

\begin{tabular}{|c|c|c|c|}
\hline $\begin{array}{l}\text { Behandiungsweise. } \\
\text { (Selbstredend uberall Atropin, } \\
\text { Verband, Bettruhe) }\end{array}$ & $\begin{array}{l}\text { Dauer } \\
\text { der Behandlung }\end{array}$ & Resultat & Bemerkungen \\
\hline $\begin{array}{l}7 \mathrm{~mm} \text { langes Rohr aus Vor- } \\
\text { derkammer gezogen. } 3 \times \\
3 \mathrm{~g} \text { Ung. cin. - Subcon- } \\
\text { junctivale Sublimat - und } \\
\text { Kochsalzinjectionen. } \\
180 \mathrm{~g} \text { Ung. cin. im Ganzen }\end{array}$ & $7 \%$ Woche & $\begin{array}{l}\text { Geheilt. } \\
\mathrm{s}=1\end{array}$ & \\
\hline $\begin{array}{l}\text { Prolaps abgetragen, Suturen. } \\
\text { Kein Hg }\end{array}$ & 11 Tage & Enucleation & $\begin{array}{l}\text { In Glaskörper Eiter } \\
\text { und ein grosses Stück } \\
\text { der Platzpatrone }\end{array}$ \\
\hline $\begin{array}{c}2 \times 3 g \text { Ung. cin. Da keine } \\
\text { Besserung nachweisbar }\end{array}$ & 5 Tage & Enucleation & $\begin{array}{l}\text { Die Section bestatigt } \\
\text { die Existent emes } \\
\text { Glaskorperabscessesin } \\
\text { der Nähe der Skleral- } \\
\text { wunde }\end{array}$ \\
\hline $\begin{array}{l}\text { Prolaps abgetragen. Sutur. } \\
\text { Kein Hg }\end{array}$ & 7 Tage & Exenteration & \\
\hline $\begin{array}{l}\text { Atropin, Sublimat, Verband, } \\
\text { Bettruhe. Nach } 3^{1} / 2 \text { Wochen } \\
\text { Entzündung geheilt, Ex } \\
\text { traction des Staars. Kein } \\
\text { Hg }\end{array}$ & $51 / 2$ Woche & $\begin{array}{l}\text { Geheilt. } \\
\mathrm{S} .=1 / 4\end{array}$ & $\begin{array}{l}\text { Nach } 3 \text { Wochen } S_{1}=1 / 2 \text {. } \\
\text { Kein Eisen gefunden }\end{array}$ \\
\hline
\end{tabular}




\begin{tabular}{|c|c|c|c|c|c|c|}
\hline Nr. & J.-Nr? & Name & 童 & $\begin{array}{l}\text { Art und Sitz } \\
\text { der Verietrumg }\end{array}$ & $\begin{array}{l}\text { Seit Ver- } \\
\text { lotzung } \\
\text { ver:- } \\
\text { fossens? }\end{array}$ & Bid der sutzün lung \\
\hline 46 & $\begin{array}{l}1897 \\
191\end{array}$ & $\begin{array}{c}\text { Hans } \\
\text { P. }\end{array}$ & 16 & $\begin{array}{l}\text { Messerstich. 4-5 }-5 m \\
\text { lange Skleralwumde; } \\
\text { Uveaprolaps. Zuerst } \\
\text { Punctionen gut }\end{array}$ & 2 Tage & $\begin{array}{l}\text { Lidodem, Chemose, diffuse } \\
\text { Glaskörpertrübung-- Nach } \\
\text { zwei Tagen gelber Reflex } \\
\text { aus Glaskörper, Ciliarkör- } \\
\text { per druckempfindhch; Iri } \\
\text { nicht deutlich entzündet }\end{array}$ \\
\hline 47 & $\begin{array}{l}1897 \\
286\end{array}$ & $\begin{array}{c}\text { Gustave } \\
\text { E. }\end{array}$ & 17 & $\begin{array}{l}\text { Gabelstich. } 1 \text { Zinke } \\
\text { durch Sklera, eine } \\
\text { durch Cornea; Iris- } \\
\text { prolaps, Wundstaar. } \\
\text { Functionen gut }\end{array}$ & 2 Tage & $\begin{array}{l}\text { Mässige Injection. Iris ver- } \\
\text { waschen, Fammerwasser } \\
\text { getrübt, Hypopyon, Ciliar- } \\
\text { körper druckempfindlich. } \\
\text { Nach zwei Tagen stärkeres } \\
\text { Pupillarexsudat }\end{array}$ \\
\hline 48 & $\begin{array}{l}1898 \\
391\end{array}$ & $\begin{array}{l}\text { Richard } \\
\text { R. }\end{array}$ & 10 & $\begin{array}{l}\text { Feilenstich, Cornea- } \\
\text { wunde, Irisprolans, } \\
\text { Wundstaar. Func- } \\
\text { tionen ungenügend }\end{array}$ & 1 Tag & $\begin{array}{l}\text { Iidödem, Chemose, Wunde } \\
\text { eitrig, Iris durch Blut ver- } \\
\text { deckt, eitriges Exsudat in } \\
\text { Torderlkammer, Ciliarkor- } \\
\text { per druekempfindlich }\end{array}$ \\
\hline 49 & $\begin{array}{c}1898 \\
440\end{array}$ & $\begin{array}{l}\text { Bertha } \\
\text { H. }\end{array}$ & 28 & $\begin{array}{l}\text { Holzsplitter, Kleine } \\
\text { Corneawunde, Wim- } \\
\text { per in Yorderkam- } \\
\text { mer, Holzsplitter- } \\
\text { chenauf rris, Wund- } \\
\text { staar. - Functionen } \\
\text { gut }\end{array}$ & $1 \mathrm{Tag}$ & $\begin{array}{l}\text { Ciliarinjection, Wunde eitrig } \\
\text { infiltirt, Kanmerwasse? } \\
\text { trüb, Hypopyon, Iris rer- } \\
\text { waschen und verförbt }\end{array}$ \\
\hline 50 & $\begin{array}{c}1898 ! \\
210\end{array}$ & $\begin{array}{c}\text { Allert } \\
\text { W. }\end{array}$ & 34 & $\begin{array}{l}\text { Pulverexplosion. } \\
\text { Mindestens } 2 \text { Cor- } \\
\text { neaperforationen. } 2 \\
\text { Pnlverktornchen und } \\
\text { - schleim anf Iris; } \\
\text { Wundstar. - Func- } \\
\text { tionen gut }\end{array}$ & $1 \mathrm{Tag}$ & $\begin{array}{l}\text { Starke Injection, Tris rer- } \\
\text { farbt und verwaschen, hl. } \\
\text { Vorderkammerexudat, Hy- } \\
\text { ponyon. Etwas Chemose. } \\
\text { Ciliarkuryer nicht druck- } \\
\text { etuptindlick. Z Znm Schluss } \\
\text { etwas Hypotonie }\end{array}$ \\
\hline 51 & $\begin{array}{c}1898 \\
552\end{array}$ & $\begin{array}{c}\text { Johann } \\
\text { D. }\end{array}$ & 60 & $\begin{array}{l}\text { Abgesprung. grösse- } \\
\text { res Holzstück. Gr. } \\
\text { Corneo-Skleral- } \\
\text { wunde, Glaskörner- } \\
\text { prolaps. Wundstaar. } \\
\text { Functionen zunähchst } \\
\text { gut }\end{array}$ & 4 Tage & $\begin{array}{l}\text { Liduden. Chemose, Iris ver- } \\
\text { färbt, Projection wird un- } \\
\text { sicher. Drtuckempfindlich- } \\
\text { keit? Kammer fehlt dauernd }\end{array}$ \\
\hline 52 & $\begin{array}{l}1898 \\
587\end{array}$ & $\begin{array}{l}\text { Errest } \\
\text { T:. }\end{array}$ & 19 & $\begin{array}{l}\text { Schlag mit nadelbe- } \\
\text { wehrter Faust. Hef- } \\
\text { tige Sehmerzen. H. } \\
\text { Corneawunde; Pro- } \\
\text { jection unten wu- } \\
\text { Nicher. Glasköryer- } \\
\text { blutung (?) }\end{array}$ & 9 Tage & $\begin{array}{l}\text { Selnstarke Injection, Wunde } \\
\text { eitrig infltrirt, Iris ver- } \\
\text { färht und verwasehen, eitri- } \\
\text { ges Forderkammerexsudat, } \\
\text { graue Exsudation im Glas- } \\
\text { körper, Clintourper drock- } \\
\text { emptindlich }\end{array}$ \\
\hline 53 & $\begin{array}{c}1899 \\
499\end{array}$ & $\begin{array}{l}\text { Kanl } \\
\text { Sch. }\end{array}$ & 9 & $\begin{array}{l}\text { Drahtstich. Cornea- } \\
\text { wunde, Wundstaar. } \\
\text { Funetionen unsicher }\end{array}$ & 5 Tage & $\begin{array}{l}\text { Leichtes Lidödem, starke } \\
\text { Injection. Wunde eitrig in- } \\
\text { filurirt, Iris verfärbt und } \\
\text { verwaschen, Kammerwasser } \\
\text { trübe, granes Pupillarexsu- } \\
\text { dat, Hypopyon, Ciliarköorr- } \\
\text { ferdruckempfindlich. Zeits- } \\
\text { weise Hypotonie }\end{array}$ \\
\hline
\end{tabular}


Zur Diagnose, Prognose u. Therapie d.perforir., inficirten Augapfelverletzungen. 31

\begin{tabular}{|c|c|c|c|}
\hline $\begin{array}{l}\text { Behandlungsweise. } \\
\text { (Selbstredend tiberall Atropin, } \\
\text { Verband. Bettruhe) }\end{array}$ & $\begin{array}{l}\text { Daxer } \\
\text { der Behandlung }\end{array}$ & Resultat & Bemerkungen \\
\hline $\begin{array}{l}\text { Abtragung, } \\
\text { naht. Kenjunctival- } \mathrm{Hg}\end{array}$ & 2 Tage & Exenteration & $\begin{array}{l}\text { Bei der Operation par- } \\
\text { tielle Glaskörperver- } \\
\text { eiterung gefunden }\end{array}$ \\
\hline $\begin{array}{l}\text { Prolaps abgetragen, Koch- } \\
\text { salzinjectionen, } 2 \times 4 \mathrm{~g} \text { Ung. } \\
\text { cin. pro die, später weniger, } \\
\text { Salicylnatron, Schwitzen. } \\
-132 \mathrm{~g} \text { Ung. cin. in toto }\end{array}$ & 6 Wochen & $\begin{array}{l}\text { Geheilt. } \\
\text { Finger in } 3 \mathrm{~m} \\
\text { wegen Staar }\end{array}$ & $\begin{array}{c}\text { Nach } 1 / 4 \text { Jahr Discision. } \\
+14 \mathrm{D} \mathrm{S} .=1 / 3\end{array}$ \\
\hline $\begin{array}{l}\text { Wunde kauterisirt, Prolaps } \\
\text { abgetragen, Atropin, Sub- } \\
\text { limat. - Kein Ung. cin. }\end{array}$ & 6 Tage & Exenteration & $\begin{array}{l}\text { Bei der Operation findet } \\
\text { sich der Glaskörper } \\
\text { vereitert }\end{array}$ \\
\hline $\begin{array}{l}\text { Wimper extralirit, Holz- } \\
\text { splitter durch Iridektomie } \\
\text { entfernt; subconjunctival } \\
\text { NaCl-Injection, } 2 \times 4 \mathrm{~g} \text { Ung. } \\
\text { cin. - Nach zelin Tagen: } \\
\text { stark quellender Staar: ex- } \\
\text { trahirt. - } 40 \mathrm{~g} \text { Ung. cin.. }\end{array}$ & 4 Wochen & $\begin{array}{c}\text { Geheilt. } \\
+13 \mathrm{D} \mathrm{S}=1 / \mathrm{s} \\
\text { Glaskörper klar }\end{array}$ & $\begin{array}{l}\text { Nach } 41 / 2 \text { Monat }+13 \mathrm{D} \\
\mathrm{S}=1 / 2\end{array}$ \\
\hline $\begin{array}{l}\text { Durch zwei gleichzeitige } \\
\text { Iridektomien Pulverkorner } \\
\text { entfernt, Kammer ansge- } \\
\text { spült; } 2 \times 3 \mathrm{~g} \text { Ung. cin. } \\
\text { pro die; subconjunctivale } \\
\text { NaCl-Injection täglich. - } \\
78 \mathrm{~g} \text { Ung. cin. }\end{array}$ & 5 Wochen & $\begin{array}{l}\text { Gebeilt. } \\
\text { Functionen gut. } \\
\text { Staar }\end{array}$ & $\begin{array}{l}\text { Nach 14 Tagen Auge } \\
\text { reizlos. Druck und } \\
\text { Functionen gut }\end{array}$ \\
\hline $\begin{array}{l}\text { Subconjuxctivale } \mathrm{NaCl}-\mathrm{In}- \\
\text { jectionen. } 6 \mathrm{~g} \text { Ung, cin. } \\
\text { pro die }\end{array}$ & 14 Tage & Enucleation & $\begin{array}{l}\text { Eiterung im vorderen } \\
\text { Glaskörperabschnitt }\end{array}$ \\
\hline $\begin{array}{l}\text { Subconjunctivale NaCl-In- } \\
\text { jectionen, } 3 \times \text { wöhentlich } \\
\text { Schwitzen, } 6 \mathrm{~g} \text { Ung. cin. } \\
\text { pro die. }-60 \mathrm{~g} \text { Ung. cin. }\end{array}$ & $6 \%$ Woche & $\begin{array}{l}\text { Geheilt. } \\
\text { Finger in } 3 \mathrm{~m} \text {. } \\
\text { Glaskörper noch } \\
\text { getrübt }\end{array}$ & $\begin{array}{l}\text { Weitere Besserung } \\
\text { sicher zu erwarten }\end{array}$ \\
\hline $\begin{array}{l}\text { Wunde kautexisirt, Kammer } \\
\text { ausgespül, Sublimat- und } \\
\text { Kochsalzinjectionen. Frst } \\
6 \text {, dann } 3 \mathrm{~g} \text { Ung. cin. pro } \\
\text { die. Schwitzen. }-123 \mathrm{~g} \\
\text { Ung. cin. }\end{array}$ & 12 Wochen & $\begin{array}{l}\text { Geheilt. } \\
+11 \mathrm{DS}<<^{1 / 5}\end{array}$ & $\begin{array}{l}\text { Nach } 1 \text { Jahr Iridek- } \\
\text { tomie und Discision. } \\
+11 \text { D S. }=1 / 2\end{array}$ \\
\hline
\end{tabular}




\begin{tabular}{|c|c|c|c|c|c|c|}
\hline Nr. & J. $-\mathrm{Nr}$ & Name & $\frac{\tilde{9}}{4}$ & $\begin{array}{l}\text { Art tund sitz } \\
\text { der Verletzung }\end{array}$ & $\begin{array}{l}\text { Solt Ver- } \\
\text { letzung } \\
\text { yer- } \\
\text { flossen? }\end{array}$ & Bild der Entaündung \\
\hline 54 & $\mid \begin{array}{c}1899 \\
504\end{array}$ & $\begin{array}{l}\text { Franz } \\
\quad \mathrm{R} .\end{array}$ & 31 & $\begin{array}{l}\text { Durch abgesprungen. } \\
\text { grosses Holzstück } \\
\text { mit Spitze. Starke } \\
\text { Schmerzen. Kleine } \\
\text { Corneo- Skleral- } \\
\text { wunde, Irisprolaps, } \\
\text { Wundstaar. - Pro- } \\
\text { jection ungenügend }\end{array}$ & & $\begin{array}{l}\text { Leichtes Lidödem, starke In- } \\
\text { jection, Wunde eitrig in- } \\
\text { filtrirt, in Vorderkammer } \\
\text { reichliches filurinds-eitriges } \\
\text { Exsudat, so dass Iris und } \\
\text { Pupille verdeckt sind; Hyp- } \\
\text { opyon; Ciliarkorper Jruek- } \\
\text { empfindlich; nach } 4 \text { Tagen } \\
\text { Hypotonie }\end{array}$ \\
\hline 55 & $\begin{array}{c}1899 \\
257 \\
u . \\
366\end{array}$ & $\begin{array}{c}\text { Franz } \\
\text { B. }\end{array}$ & 17 & $\begin{array}{l}\text { Drahtstich. Kleine } \\
\text { Hornhautwunde, } \\
\text { Wundstaar.-Func- } \\
\text { tionen genügend }\end{array}$ & $1 \mathrm{Tag}$ & $\begin{array}{l}\text { Starke Injection, Iris stark } \\
\text { verwaschen und verfärbt, } \\
\text { leichteres Vorderkammer- } \\
\text { exsudat, Hyponyon, Ciliar- } \\
\text { korper druckempfindlich. } \\
\text { - Später Descem et' sche } \\
\text { Beschlage }\end{array}$ \\
\hline 56 & $\begin{array}{c}1899 \\
55\end{array}$ & $\begin{array}{l}\text { August } \\
\text { E. }\end{array}$ & 47 & $\begin{array}{l}\text { Abgesprungen. Stein- } \\
\text { splitter. Kleine Cor- } \\
\text { neawunde, Irisad-1 } \\
\text { häsion, Wundstaar }\end{array}$ & 2 Tage & $\begin{array}{l}\text { Starke Injection, Iris ver- } \\
\text { färbt mandrerwaschen; klei- } \\
\text { nes Pupillarexsudat, Hyyo- } \\
\text { pyon }\end{array}$ \\
\hline 57 & $\begin{array}{l}1899 \\
542\end{array}$ & $\begin{array}{c}\text { Wanda } \\
\text { P. }\end{array}$ & 17 & $\begin{array}{l}\text { Hakenstich. Grosse } \\
\text { Corneawunde, mit } \\
\text { Iris - und Glaskör- } \\
\text { perprolaps; trauma- } \\
\text { tisches lriscolobom. } \\
\text { Functionen genï» } \\
\text { gend }\end{array}$ & 1 Tag & $\begin{array}{l}\text { Lidodem, Chemose, Iris ver- } \\
\text { waschen u. verfäbt, ziem- } \\
\text { lichgrosses Vorderkammer- } \\
\text { exsudat, Ciliarkörper oben } \\
\text { aussen druckempfindlich, } \\
\text { ebendort gelber Schein aus } \\
\text { der Tiefe }\end{array}$ \\
\hline 58 & $\begin{array}{l}1900 \\
356\end{array}$ & $\begin{array}{l}\text { Ludwig } \\
\text { G. }\end{array}$ & 22 & $\begin{array}{l}\text { Abgesprung. Nagel. } \\
\text { Skleral wunde mit } \\
\text { Uveaprolaps }\end{array}$ & 3 Tage & $\begin{array}{l}\text { Leichtes Lidödem und Che- } \\
\text { mose. Wunde eitrig be- } \\
\text { legt, Iris stark verfärbt und } \\
\text { verwaschen, grosses fibri- } \\
\text { noses Yorderkammerexsu- } \\
\text { dat, Ciliarkörler etwis } \\
\text { druckemptindlich; gelb- } \\
\text { grauer Retlex aus Glas- } \\
\text { korper. - Später Desce- } \\
\text { met"sche Beschläge }\end{array}$ \\
\hline 59 & $\begin{array}{l}1901 \\
525\end{array}$ & $\begin{array}{c}\text { Albert } \\
\mathrm{K} .\end{array}$ & 45 & $\begin{array}{l}\text { Abresprung. Eisen- } \\
\text { splitter. Kleine Skle- } \\
\text { ralwunde; Eisen im } \\
\text { Ciliarkörper }\end{array}$ & 2 Tage & $\begin{array}{l}\text { Starke Injection, später Che- } \\
\text { mose, Iris verwaschen und } \\
\text { verfärbt, starkes Vorder- } \\
\text { kammerexsudat, Hypo- } \\
\text { pyon, Eiter im Glasköper } \\
\text { sichtbar, Ciliarköperleicht } \\
\text { druekempfindheh }\end{array}$ \\
\hline 50 & $\begin{array}{c}1901 \\
89\end{array}$ & $\begin{array}{c}\text { Karl } \\
\text { R. }\end{array}$ & 51 & $\begin{array}{l}\text { Seit 45. nach Mörser- } \\
\text { explosion Irisprolaps } \\
\text { in der Sklera nahe } \\
\text { dem Limbus. Spon-- } \\
\text { tane Spätinfeetion } \\
\text { desselben vor }\end{array}$ & 2 Tagen & $\begin{array}{l}\text { Auge stark injicirt, Iris ver- } \\
\text { waschen und verfärbt, dich- } \\
\text { tes Pupillarexsudat, Ifam- } \\
\text { merwasser trub, Hypopyon, } \\
\text { Ciliarkurperdruckemptind- } \\
\text { lich. An Stelle des Prolapses } \\
\text { ein granes Geschwur in der } \\
\text { Sklera }\end{array}$ \\
\hline
\end{tabular}


Zur Diagnose, Prognose u. Therapie d. perforir., inficirten Augapfelverletzungen. 33

\begin{tabular}{|c|c|c|c|}
\hline $\begin{array}{l}\text { Behandlungsweise. } \\
\text { (Selbstredend überall Atropin, } \\
\text { Verband, Bettrnhe) }\end{array}$ & $\begin{array}{c}\text { Dauer } \\
\text { der Behandlung }\end{array}$ & Rasultat & Bemerkungen \\
\hline $\begin{array}{l}\text { Hydrarg. bij. intramusculär; } \\
2 \times 4 \mathrm{~g} \text { Ung. cin.; subcon- } \\
\text { junctival Sublimat }\end{array}$ & 10 Tage & Enucleation & $\begin{array}{l}\text { Section ergiebt einen } \\
\text { Glaskörperabscess }\end{array}$ \\
\hline $\begin{array}{l}\text { Subconjunctivale Sublimat- } \\
\text { injectionen, } \mathrm{Hg} \text { bijod. in } \\
\text { die Glutäen, } 2 \times 3 \mathrm{~g} \text { Ung. } \\
\text { cin. pro die. }-120 \mathrm{~g} \text { Ung. } \\
\text { cin. }\end{array}$ & 5 Wochen & $\begin{array}{l}\text { Geheil t. } \\
\text { Finger in } 50 \mathrm{~cm} . \\
\text { Staar }\end{array}$ & $\begin{array}{l}\text { Nach } 4 \text { Wochen Ex- } \\
\text { traction. +15D S. }=1\end{array}$ \\
\hline $\begin{array}{l}\text { Täglich subconjunctiv. Sub- } \\
\text { limat-, später Kochsalzin- } \\
\text { jection. } 2<3 \text { Ung.cin.täy- } \\
\text { lich. }-54 \mathrm{~g} \text { Ung. cin. }\end{array}$ & $3 / 2$ Wochen & $\begin{array}{c}\text { Geheilt. } \\
\text { Finger in } 50 \mathrm{~cm} . \\
\text { Staar }\end{array}$ & $\begin{array}{l}\text { Nach } 2 \text { Monaten Dis- } \\
\text { cision und Extraction. } \\
+12 \text { D } S=\% / \text { so. Pu- } \\
\text { pille noch nicht klar; } \\
\text { Besserungzaerwarten }\end{array}$ \\
\hline $\begin{array}{l}\text { Täglich, später zweitäglich, } \\
\text { subconjunctivale Sublimat- } \\
\text { injection. Prolapsabtragung. } \\
2 \times 3 \text { g Ung. cin. täglich, } \\
\text { später Jodkalium und } \\
\text { Schwitzen. }-72 \text { g Ung. } \\
\text { cin. in } 16 \text { Tagen }\end{array}$ & $5 \%$ Wochen & $\begin{array}{c}\text { Geheilt. } \\
\mathrm{S} .=1 / 7 \\
\text { Nach unten Glas- } \\
\text { körpertrubungen }\end{array}$ & $\begin{array}{l}\text { Nach } 3 \text { Wochen } \mathrm{S}=1 / 3 . \\
\text { Glaskörper noch nicht } \\
\text { ganz klar }\end{array}$ \\
\hline $\begin{array}{l}\text { Täglich subconjunctiv. Sub- } \\
\text { limatinjection, Hg. bijod. in } \\
\text { die Glutäen, } 2 \times 4 \mathrm{~g} \text { Ung. } \\
\text { cin. täglich. Zuerst } 96 \mathrm{~g} \\
\text { Cng. cin., beim Recidiv } \\
186 \mathrm{~g} \text { Ung. cin. }\end{array}$ & $13 \%$ Wochen & $\begin{array}{c}\text { Geheilt. } \\
\text { S. }=1 / 4 . \\
\text { Nach } 4 \text { Wochen } \\
\text { S. }=1 / 2 \\
\text { Noch Glaskorper- } \\
\text { trübungen }\end{array}$ & $\begin{array}{l}\text { Nach Aussetzen des } \\
\text { Ung. cin. } 4 \text { Wochen } \\
\text { nach der Aufnahme } \\
\text { trat ein Recidiv mit } \\
\text { Hypopyon auf, das } \\
\text { nochmals viel Cng. } \\
\text { cin. nothig machte }\end{array}$ \\
\hline $\begin{array}{l}\text { Splitter mit Magneten extra- } \\
\text { hixt. Hg bijod. in die Glu- } \\
\text { täen, taglich subconjunc- } \\
\text { tivale Sublimat-, später } \\
\text { NaCl-Injectionen. } 2 \times 49 \\
\text { Ung. cin. - } 153 \text { g Ung. cin. }\end{array}$ & $5 \%$ Wochen & $\begin{array}{c}\text { Geheilt. } \\
\text { S.> } 8 / 3^{\circ} \\
\text { Noch flottirende } \\
\text { Trübungen im } \\
\text { Glaskörper }\end{array}$ & $\begin{array}{l}\text { Nach } 6 \text { Wochen Visus } \\
\text { idem. In der Wund- } \\
\text { gegend noch Exsudat- } \\
\text { reste im Glaskörper } \\
\text { sichtbar }\end{array}$ \\
\hline $\begin{array}{l}\text { Prolaps kauterisirt, Sublimat } \\
\text { subconjunctival, } \mathrm{Hg} \text { bijod. } \\
\text { in die Glutäen, } 6 \mathrm{~g} \text { Lng. cin. } \\
\text { täglich. }-54 \mathrm{~g} \text { Ung. cin. }\end{array}$ & 4. Wochen & $\begin{array}{l}\text { Geheilt. } \\
S .=1 / 10 \\
\text { Alte Maculae } \\
\text { corneae }\end{array}$ & $\begin{array}{l}\text { Perforationsstelle nach } \\
3 \text { Wochen durch } \\
\text { Bindehautlappen. ge- } \\
\text { deckt }\end{array}$ \\
\hline
\end{tabular}


Wie ich bei der Uveitis fibrinosa hervorgehoben hatte, dass für die Prognose die Existenz eines Glaskörperabscesses ron ausschlaggebender Bedeutung ist, so finde ich dies anch bei der Uveitis purulenta wieder. In allen sieben zur Enucleation oder Exenteration gekommenen Fällen fand sich Eiter im Glaskörper. Nun könnte man denken, dass hiermit für die Prognose wenig gewonnen wäre, da eben erst die Entwicklung dieser Eiterung das Signal zur Entfernung des Bulbus gegeben habe. Die obige Tabelle zeigt aber, dass im Gegensatz zu den Erregern der fibrinösen Entzündungen den Eiterbakterien - relativ - keine besonders grosse Nejgung zukommt, nach hinten zu wandern. In allen Fällen, wo die Section oder die klinische Untersuchung $(57,58,59)$ die Existenz eines Glaskörperabscesses sicher stellte, war die Verletzung bis ins Corpus vitreum gedrungen, und der Abscess schon bei der Aufnahme vorhanden. Nur in Fall 48 ist nicht aus der Lage der Wunde oder einem Glaskörperrorfall mit Sicherheit zu erselien, dass die Verletzung bis ins Corpus gedrungen war; höchst wahrscheinlich aber ist es auch hier, da bereits am zweiten Tage nach dem Trauma die klinischen Symptome des Glaskörperabscesses vorhanden waren.

Eine Ausnahme macht allein Fall 52. Hier sass die Wunde in der Hornhaut und die Linse war intact geblieben; ein Eindringen der Nadel bis in das Corpus war also nicht gerade wahrscheinlich. Wewn hier trotzdem schon bei der Aufnahme eine gleichmässige graue Infiltration des Corpus nachweisbar war, also ein Weiterkriechen der Bakterien nach hinten angenommen werden muss, so ist zu bedenken, dass gerade dieser Kranke erst am neunten Tage nach dem Trauma in die Klinik eintrat und energisch antibakteriell behandelt wurde; bis dahin waren nur "Augentropfen" und ein Verband angewandt worden.

Wir muissen hieraus schliessen, dass auch bei der eitrigen Entzündung des Augenimneren der Glaskörperabscess in der Regel durch directe Infection des Glaskörpers bei der Verletzung, also primär, entsteht; nicht durch Propagation der Bakterien aus der Iris nach hinten. Dafür spricht weiter der giinstige Verlanf in den sechs Fällen, bei welchen bei der Aufnahme der Glaskörper mit grösster Wahrseheinlichkeit noch frei war, bei welchen eine einfache eitrige Iritis $(45,49,50,56)$ oder Irido-Cyclitis $(41,55)$ vorlag. Alle sind zur Heilung gekommen, ohne dass der Glaskörper in Mitleidenschaft gezogen wurde.

Frage ich auch hier wieder nach den kinischen Srmutomen der 
unsichtbaren Glaskörpereiterung; so weist die Tabelle auf die gleichen Anzeichen hin, die schon bei der Uveitis fibrinosa als charakteristisch gefunden waren: Schnell auftretende, ausgedehnte und dichte fibrinöse oder fibrinös-eitrige Exsudation in die Vorderkammer und Ciliardruckschmerz.

Leider sind die beiden Symptome nicht immer so ausgeprägt vorhanden und nicht so für den Glaskörperabscess allein reservirt, dass sie eine sichere Diagnose in allen Fällen gestatteten. Nur unter Berücksichtigung des ganzen Krankheitsbildes wird man hier zu einer Entscheidung gelangen, und auch daun werden immer noch Fälle übrig bleiben, wo wir schwankend sind oder einen Irrthum begehen. So wird uns die Intensität der entzündlichen Injection, resp. der Chemosis, und die Schnelligkeit ihres Auftretens gewisse Anhaltspunkte geben; wir werden ein etwaiges Lidödem in den Kreis unserer Betrachtungen ziehen; beides aber fehlt nicht selten beim Glaskörperabscess und ist bei einfacher Iritis vorhanden. Viel wichtiger ist die Art der Verletzung und der Sitz der Wunde, die Frage, ob die Verletzung den Glaskörper selbst mit betroffen hat. Wie ich schon sagte, entstehen fast ausschliesslich durch solche bis in das Corpus vitreum penetrirende Wunden diese Abscedirungen. Das Hauptgewicht aber meine ich, wie oben erwähnt, auf reichliche Exsudation in die Vorderkammer und den Ciliardruckschmerz legen zu müssen.

Zehn absolut sichere Fälle von Glaskörperabscess sind in obiger Tabelle enthalten; in dreien war derselbe in vivo sichtbar, als gelber Reflex aus der Tiefe, sieben Mal wurde die Diagnose durch die Section erbärtet. Sehr reichliches, theils rein grauliches, theils graugelbliches Vorderkammerexsudat fand sich in sieben von diesen zehn Fällen $(42,44,48,52,54,57,58,59)$. Stets enthielt es so viel Fibrin, dass es in continuirlicher Schicht die Oberfläche der Iris und Pupille überziehen konnte und nicht einfach als Hypopyon zu Boden sank. Von den restirenden drei Fällen scheidet der eine (Nr. 51) aus der Betrachtung aus, weil hier dauernd die Vorderkammer fehlte, in den beiden anderen (Nr. 43 und 46) aber waren die iritischen Erscheinungen sehr gering, nur leichte Verwaschenheit und Verfärbung der Tris, leichte Kammerwassertrübung, kein Hypopyon, kein fibrinöses Exsudat. Beide Male handelte es sich nm reine Glaskörperinfection und um noch kleine Abscesse, die Wunde sass in der Sklera und hatte nicht die Cornea perforirt; die iritischen Erscheinungen waren also als reine Toxinwirkung zu deuten; in der Iris 
befanden sich keine Eitererreger. In diesen Füllen also lässt das in Rede stehende Symptom im Stich, wie ïbrigeus von den metastatischen Abscessen her bekannt ist; hier brauchen wir es aber auch nicht, da der Einblick in den Glaskörper fiei ist. Es reicht augenscheinlich die Toxinwirkung nicht aus, die normale Iris zu reichlicher Exsudation anzuregen, während die schon durch directe Bakterienwirkung entzündete Iris viel leichter in dieser Richtung zu beeinflussen zu sein scheint. Das aber, glaube ich, dïrfen wir als allgemeinen Satz aufstellen: Wo innerhalb der ersteu drei Tage ein so massiges, lockeres, fibrinöses oder fibrinös-eitriges Exsudat in der Vorderkammer entsteht, dass auch bei weiter Pupille jeder Einblick in den Glaskörper unmöglich ist, findet man fast regelmässig einen Glaskörperabscess. Einfache eitrige Iritis bedingt in erster Linie Eiterbildung in der Forderkammer mit geringer fibrinöser Exsudation, und rein fibrinöse Iritis oder Irido-Cyclitis producirt überhaupt nur selten so reichliche Exsudatmengen, jedenfalls aber erst in längerer Zeit.

Druckempfindlichkeit des Ciliarkörpers, zumal in der dem Abscess benachbarten Gegend ist ein selur frühes und sehr constantes Symptom. Mit Ausnahme eines Falles (Nr. j1), wo vergessen ist, über Druckempfindlichkeit zu berichten, kehrt es in allen Krankengeschichten wieder und war oft in sehr hohem Masse vorhanden. Es kommt aber nicht allein dem Glaskörperabscess zu, sondern auch der einfachen Oyclitis, und fand sich so auch in den Fällen 41 und 55. Das ist nicht auffallend, denn in beiden Fällen ist ja der Ciliarkörper entziundet und der Unterschied besteht nur darin, dass beim Abscess die Bakterien oder wenigstens die Hauptmenge der Bakterien im Glaskörper sitzen $\left.{ }^{1}\right)$ und von hier aus dureh ihre Toxine den Ciliar-

1) Auch ich balte mit Straub die Unterscheidung zwischen Glaskörperabscess und Cyclitis für durchans wünschenswerth und sehr wohl durchführbar. Nur gegen den Namen Hyalitis sträube ich mich, da ich für das Wesentliche in der Entzündung eines Gewebes halte, dass dasselbe durch Proliferationsrorgarnge seiner Zellen activen Antheil an dem Proeess nimmt und nicht nur Stapelplatz der Entzündungserreger und der eingewanderten Leukocyten ist. Sonst muss man ja auch von einer Phakitis und von einer Aqueitis sprechen, weun die Bakterien in der Linse oder im Kammerwasser deponirt sind. Ist aber erst der Beweis, dass Glaskörperzellen sich an der Entzündung activ betheiligen, einwandsfrei erbracht, dann würde auch ich den Ausdruck Hyalitis suppurativa für durchans zweckmässig halten; denn dass es für das klinische Bild einen grossen Unterschied ausmacht, ob die Bakterien im Glaskörper oder im Ciliakörper sitzen, steht über jeden Zweifel. 
Zur Diagnose, Prognose u. Therapie d. perforir., inficirten Augapfelverletzungen. 37

körper in Entzïndung versetzen, während bei der eigentlichen Cyclitis die Bakterien im Gewebe des Ciliarkörpers sich befinden und hier eitrige Infiltration erzeugen, während der Glaskörper unberührt bleibt, vielleicht bis auf etwas Leukocytenansammlung in seinen äussersten Randschichten. Uebrigens ist mir kein einziger Sectionsbefund ron eitriger Cyclitis oder Irido-Cyclitis bekannt, während man die fibrinösen Cyclitiden, z. B. in sympathisirenden Augen oder bei Tuberculose, doch nicht so selten sieht. Es spricht dies wieder für meine schon oben ausgesprochene Ansicht, dass die Eiterbakterien keine besonders grosse Tendeuz haben, im Gewebe nach hinten zu wandern, während die Erreger der fibrinösen Uveitiden in hohem Masse hierzu neigen.

Schliesslich wäre noch zu erwähnen, dass ein geheilter Abscess noch sehr lange Zeit Trübungen im Glaskörper zurücklässt. In keinem von den vier geheilten Abscessen $(52,57,58,59)$ habe ich bisher die völlige Klärung des Glaskörpers beobachtet, obgleich die Sehschärfe in zweien schon wieder fast normal war, und obgleich schon eine Reihe ron Wochen seit dem Ablauf der letzten entzündlichen Erscheinungen verstrichen war. In Fällen, wo anfangs Medientrïbungen eine sichere Diagnose urmöglich machten, könnte dies Verhalten später von Wichtigkeit werden und eine nachträgliche Diagnose ermöglichen.

Folgende Krankengeschichten mögen zur Illustrirung des eben Gesagten dienen.

1. Wanła P. (Nr. 57). Geheilter Glaskörperabscess.

Das Dienstmädchen Wanda P., 17 Jahre alt, stiess sich am 14. II. 1899 mit einem grossen Haken ins linke Auge. Am gleichen Abend findet sich mässige eiliare Injection, eine grosse Hornhautwunde oben aussen dicht am Limbus und ilım parallel, ihre Ränder graulich gefärbt; zwischen ihnen Iris und einzelne Glaskörperfäden; in der Wundgegend grosses Iriscolobom, die Vorderkammer fast ganz voll Blut; Ciliarkörper oben aussen leicht druckempindlich; Functionen genügend. Atropin-Sublimatsalbe, Verband.

15. II. Patientin hat in der Nacht Schmerzen gehabt. Starkes Oedem des oberen Lides und starke Chemose. In der Vorderkammer neben dem Blut ein dichtes fibrinös eitriges Exsudat sichtbar, das gerade noch einen gelben Reflex aus der Tiefe in der Wundgegend erkennen lässt. Druckempfindlichkeit hat zugenommen. Ther. eadem, ausserdem täglich subconjunetivale Sublimatinjection, zwei Theilstriche und $2 \times 3 \mathrm{~g}$ Ung. cin. einreiben.

16. II. Sämmtiche Erscheinungen haben zugenommen; der Bulbus soll exenterirt werden. Da andere Operationen drängten, verschob ich den Eingriff auf den Nachmittag. Als die Kranke nachmittags schon auf dem Operationstisch lag, selien miv die Chemose etwas schlaffer zu sein, und ich beschloss daher, noch zu warten und die Therapie fortzusetzen. 
Am 17. II. und den folgenden Tagen hielt die Besserung an. Die Chemose ging zurück, das Exsudat begann zu schrumpfen und zog sich nach der Wunde lin zusammen; man sah jetzt die stark entzündete Iris zum Vorschein kommen. Die Schmerzen liessen nach. Rothes Licht ist auch durch die exsudatireien Stellen des Pupillargebietes nicht zu erhalten, da der ganze Glaskörper diffus getribt ist.

20. II. Der Irisprolaps wird abgetragen, starke Blutung in die Vorderkammer, die sich nur langsam resorbirt. Die entzïndlichen Erscheinungen: gehen dabei stetig weiter zuruck. Am 25. II. ist das Pupillarexsudat völlig resorbirt, das Kammerwasser fast klar, Pupille gut weit, Ciliarkörper nicht mehr druckempfindlich; Fingerzählen in $5 / 4 \mathrm{~m}$. Fom 1. MI. ab werden bie Sublimatinjectionen nur noch jeden zweiten Tag gemacht; am 5. II. steht Patientin zum ersten $\mathrm{Mal}$ auf; im stets blarer werdenden Glaskörper grosse flotirende Opacitaten. Zweimal wöchentlich Schwitzen und Jodkalium; die Schmiercur wird ansgesetzt.

Am 25. III. wird die Kranke mit blassem, reizlosem Auge entlassen. Im Glaskörper noch zahlreiche Trübungen, Papille nur sehr versehleiert sichtbar, E. S. $<^{1 / 7}$.

Am 15. IV. ist der Glaskörper wesentlich klarer, enthält aber noch zahlreiche Flocken; Papille viel deutlicher. E. S. $=1 / 3$. Seitdem hat sich Patientin nicht wieder vorgestellt.

2. Franz R. (Nr. 54) Unsichtbarer Glaskörperabseess. Diagnose durel Section bestätigt.

Dem 31 jälnigen Arbeiter Franz R. flog beim Holzspalten am 17. XII. 1899 ein grösseres Stück Holz mit scharfer Spitze gegen das linke Auge. In den ersten zwei Tagen waren die Schmerzen gering, in der dritten Nacht aber stellten sich heftige Schmerzen ein, die Patienten veranlassten, sich am 20. XII. hier aufnehmen zu lassen.

Leichtes Oedem beider Lider, starke gemischte Injection. Am äusseren Limbus ea. $3 \mathrm{~mm}$ lange horizontale Wunde, der mit gelblichem Exsudat bedeckte Iris eingelagert ist. Kammerwasser sehr stark getrübt, grosses fibrinöseitriges Exsudat in der Vorderkammex, das die Iris und den Einblick in den Glaskörper völlig verdeckt. Hyphaema. Ciliarkörper oben und temporal druckempfindlich; Projection felit unten uad nasal.

Tägliche subconjunctivale Sublimatinjection, Hydrargyrum bijodatum intramusculär, $2 \times 4 \mathrm{~g}$ Ung. cin. einreiben, Atropin-Sublimatsalbe, feuchter Verband.

Bei dieser Therapie schien in den ersten Tagen Besserung einzutreten; das Ange wurde etwas blasser und das Vorderkammerexsudat zog sich etwas in sich zusammen. Aber schon am vierten Tage begann der Tonus zu sinken, die Cornea erschien leicht queroval, und am Boden der Kammer sammelte sich ein Hypopyon. Deshalb am 30. XII. Enucleatio bulbi.

Die Section bestätigte die aus obigen Symptomen auf Glaskörpereiterung gestellte Diagnose und wies einen mittelgrossen, circumscripten Abscess in der Wundgegend dicht am Ciliarkörper mach.

3. Hans P. (Nr. 46). Glaskörperabscess ohne Iritis.

Der 16 jährige Lehrling Hans P. stiess sich am 19. VI. 1897 mit einem Selnitzmesser ins linke Auge. Am folgenden Tage findet sich leichtes 
Zur Diagnose, Prognose u. Therapie d. perforir, inficirten Augapfelverletzungen. 39

Lidödem und Conjunctivalchemose. Aussen von der Cornea eine $5 \mathrm{~mm}$ lange Skleralwunde, in der Uveatheile mit eitrigem Schleim bedeckt liegen. Vorderkarnmer sehr tief, aber ohne Exsudation, Iris nicht verwaschen, Glaskörper diffus getribt; vom Mintergrund nichts zu sehen. Prolaps abgetragen, Conjunetiva genäht, Atropin-Sublimatsalbe, feuchter Verband.

Drei Tage später bestehen spontane Schmerzen, die Chemosis hat zugenoramen, Ciliarkörper stark druekempfindlich, aus dem Glaskörper und der Wundgegend intensiv gelber Reflex; dabei keine dentlichen Entzïndungserscheinungen an der Iris. Bei der Exenteration findet sich eine partielle Abscedirung des Glaskörpers.

Vorübergehende Hypotonie wurde wie bei der fibrinösen Uveitis, so auch hier zwei Mal beobachtet $(50,53)$; Hohllegen des Auges durch Aluminiumplatte schien von günstiger Wirkung zu sein.

Bemerkenswerth ist weiter, dass in drei Fällen $(41,55,58)$ nach Ablauf der eitrigen Fntzündung, als ich die energische Quecksilberapplication eingeschränkt hatte, ein leichtes Fntzündungsrecidiv mit Bildung Descemet'scher Beschläge, aber ohne jede Spur von Eiterung sich einstellte. Wer erst in diesem Stadium die Augen sah, hätte unmöglich vermuthen können, dass hier eine schwere Eiterung voraufgegangen war; er hätte eine einfache seröse oder wegen der hinteren Synechien serös-fibrinöse Trido-Cyclitis diagnosticirt.

Zwei Erklärungen scheinen mir möglich für dies höchst auffällige Verhalten. Entweder es waren neben den Eitererregern auch Erreger der serös-fibrinösen Entzündung eingedrungen, sie waren uicht, wie die Fitererreger, dem Quecksilber erlegen und begannen nun, nachdem die Quecksilberwirkung nachgelassen und das klinische Bild nicht mehr durch die Eitererreger dominirt wurde, die für sie charakteristische, chronische Entzündung zu erregen. Wahrscheinlicher ist mir indess, dass die pyogenen Bakterien zum Theil noch nicht abgetödtet waren, als ich mit der Quecksilberapplication nachliess, dass sie sich wieder erholten und vermehrten, nunmehr aber, da sie stark in ihrer Virulenz geschwächt waren, keine Eitorung mehr, sondern nur diese chronische serös-fibrinöse Entziindung erzeugten. Diese Anschauung findet eine Stütze in der bekannten, zuerst wohl von Deutschmann bervorgehobenen Thatsache, dass man am Kaninchenauge durch Einimpfung von Staphylocoklen jede Form von Entzündung von schwerster Fiterung bis, zur chronischfibrinösen Entzündung hervorrufen kann, je nachdem man vollvirulente oder abgeschwächte Culturen verwendet.

1. Ferdinand R. (Nr. 41). Trido-Cyclitis purulenta, später Irido-Cyclitis serosa.

Der Knecht Ferdinand R., 29 Jahre alt, stiess sich am 24. IX. 1895 beim Bücken ein Rohr in das linke Auge. Sehr heftige Sohmerzen. 
Zwei Tage später bietet das Auge folgenden Befuna: Mässige gemischte Injection, nahe dem inneren Cornearand ein stecknadekopfgrosses eitriges Infiltrat in der Homhant mit dunklem Punkt in der Mitte; von hier zieht ein stecknadeldieker gelblicher Streif hinter den Skleralrand; Kammerwasser trüb, kleines Hypopyon, Iris sehr stark verwaschen und verfärbt; graues Pupillarexsudat, Ciliarkörper druckempfindlick. Functionen genügend. Ich suchte sofort den dmiklen Fremdkörper za entfernen und extrahirte mit der Pincette ein $7 \mathrm{~mm}$ langes Stück Rohr, das ganz in Eiter eingehüllt gewesen war. Abwechselnd Sublimat- und Kochsalzinjection, $3 \times 3 g$ Ung. cin., reichlich Atropin, feuehter Verband.

Sehon am nächsten Tage begann die Entzündang nachzulassen; die Exsudate resorbirten sich, so dass am 30. IX. sehon $S .=1 / 5$ war, und ich auf $6 \mathrm{~g}$ Ung. cin. täglich herabging und rom 3 . $\mathrm{X}$. ab das Schmieren ganz aussetzte. Wie der Erfolg zeigte, zu fruh. Bis zum 14. X. ging Alles gut. Dann aber injicirte sich das schon völlig blasse Auge wieder, die Iriszeichnung schien etwas verwaschener und es traten Beschläge an der RückHäche der Cornea und an der Linsenkapsel auf. Im Hintergrund erschienen die Netzhantvenen erweitert. Abermals Inunctionen, $4 \mathrm{~g}$ täglich und jeden zwoiten Tag Schwitzen.

Jetzt machte die Entztindung zwar keine weiteren Fortschitte; es bedurte aber dreier Touren Inunctionen, bis das Auge mieder entzindungsfrei und die Beschläge resorbirt waren. Am 6. XT. wird Patient mit klaren brechenden Medien und normalem Fundus entlassen. Nur auf der Linsenkapsel sind mit der Lape noch feinste Pünktchen sichtbar. E, S. $=1$.

Fall 2: Franz B. (Nr. 55). Irido-Cyclitis purulenta, später IridoCyelitis serosa.

Dem 17jänigen Sehmiedelelming Franz B. flog am 27. VII, 1899 ein langer Dralnt gegen das linke Auge. Die Schmerzen waren sofort so heftig; dass er bereits an folgenden Tage in die hiesige Klinik kam. Es fand sich leichte Röthng der Lidhaut ohne Oedem, starke gemischte Injeetion, oben innen kleine infiltrirte Hornhautwunde, Iris stark verwaschen und rerfärbt, kleines Pupillarexsudat, Lammerwasser stark getrübt, Hypopson, Wundstaar, Ciliarkörper druckempfindlich, Functionen gut. - Täglich subconfunctivale Sublimatinjectionen und $2 \times 3 \mathrm{~g}$ Ung. cin., AtropinSublimatsalbe, teuchter Verband. $1 \times 0,01$ Hydrargyrum bijodatum in die Glutäen.

Nachdem in den nächsten zwei Tagen noch etwas Chemose himzagetreten war, beginnt am 31 . VII. die Besserung und machte so gnte Fortschritte, dass ich an 10. VIII. jede Quecksilberapplication sistirte. Aber schon am 12. VIIr. trat stärkere Injection auf, die Pupille reagirte nicht wehr so gut auf Atropin, und an der Hombautrückffäche zeigten sich eine Anzahl feiner Beschläge. Neuerdings $4 \mathrm{~g}$ Ung. cin. täglich, zwei Mal wöchentlich Schwitzen, subconjunetivale Kochsalzinjectionen. Am 20. VIII. ist die Entzindung im Wesentlichen abgelaufen, de Beschlage versehwunden. Im 29. VIII. wind Patient mit Atropin entlassen. Die Cataract ist fast l'eif, Fingexzählen in $50 \mathrm{~cm}$.

Am 26. IX. kommt er zur. Extraction wieder. Dieselbe nimmt normalen Verlauf; am 16.X. ist mit +16 D S. $<1 / 2 ;$ am 29 . VIII. 1900 mit +15 D S. $=1$. 
Zur Diagnose, Prognose u. Therapie d. perforir., inficirten Augapfelverletzungen. 41

\section{Therapie.}

Die traumatisch-infectiösen Uveitiden stellen eine so schwere und der Therapie bisher so wenig zugängliche Erkrankung dar, dass wir von allen uns zu Gebote stehenden therapeutischen Methoden geeigneten Falles Gebrauch machen müssen und niemals schematisch eine einzige Massnahme in allen Fällen anwenden sollten.

Neben dem stets indicirten Atropin, feuchter Wärme und Verband kommt in allen Fällen von frischer eitriger Entzündung die Galvanokaustik in Betracht. Durch Verschorfung der Wundränder und Einführung der Glïhschlinge in die eitrig infiltrirte Nachbarschaft der Wunde gelingt es in manchen Fällen, alle Mikrobien abzutödten, so den eitrigen Process zu coupiren und das Auge schnell der Heilung zuzuführen. Auf diese Weise diurfte z. B. wohl in den beiden ersten Fällen van Millingens ${ }^{1}$ ) die schnelle Wirkung der Galvanokaustik zu erklären sein. Dieselben lehren zugleich, dass der Glaskörper die energische Einführung der Glühschlinge sehr gut vertragen kann, da in beiden Fällen ausgezeichnete Sehschärfe resultirte. $\mathrm{Ob}$ er es freilich immer thut, ob nicht zuweilen Netzhautablösung die Folge ist, müssen erst weitere Erfahrungen lehren. Liegt die Perforation in der Hornhant, so beobachtet man bisweilen eitrige Iritis ohne eitrige Infiltration der Wundränder; hier würde natürlich die Galvanokaustik verkehrt sein.

Aber auch wo man nicht mehr hoffen darf, das Auge völlig von den Infectionserregern zu säubern, erscheint es rationell, einen möglichst grossen Theil von ihnen zu beseitigen. Dies erreichen wir auch in den schon vorgeschrittenen Fällen von Uveitis purulenta durch Verschorfung der Wundränder und des Haupteiterherdes. Bei der Uveitis fibrinosa dürfte diese Methode nur ausnahmsweise Anwendung finden, da die Wunde in der Regel primär glatt verheilt und der Hauptsitz der Mikrobien sich nicht so augenfällig verräth.

Weiter köunen wir dies Ziel durch Punction der Vorderkammer erreichen, eine Methode, die ich bei Sitz der Wunde in der Hornhaut bevorzuge. Mit dem Kammerwasser und den Vorderkammerexsudaten wird sicher ein erheblicher Theil der Mikrobien aus dem Angeninneren entfernt. Vielleicht noch günstiger als die Punction mit der Lanze wirkt hier die von Eversbusch so warm empfohlene Paracentese mit der Glühschlinge (Glauning, Ueber die Behand-

I) Ueber endo-oculäre Gal ranokaustik. Centralbl. f. Augenheilk. 1899. S. 161. 
lung inficirter, perforirender Bulbuswunden. Diss. Erlangen, 1900). Die locheisenartige Oeffnung soll hier noch stundenlang das Kammerwasser allmählich absickern lassen, und es erscheint wohl zweifellos, dass durch diese Verminderung des intraocularen Druckes eine arterielle Hyperämie im Bubusinneren erzeugt wird, die durch bessere Ermährung der Gewebe und Steigerung des ganzen Stoffwechsels eine günstige Rüekwirkung auf die Entzündung auszuäben im Stande ist. Glauning berichtet über vier durch diese Methode geheilte Fälle, ron welchen allerdings drei das qualitative Sehen eingebuisst hatten und zwei nach ihrer Entlassung sich nicht wieder vorgestellt haben, so dass das definitive Resultat ungewiss bleibt. In wie viel Eällen die Methode vergeblich angewandt wurde, erfahren wir leider nicht.

In einer Anregung der Circulation, speciell der Lymphcirculation, haben wir auch die günstige Wirkung der subconjunctivalen Injectionen zu erblicken. Dass dabei an eine baktericide Wirkmng der eingefïhrten Quecksilbersalze nicht zu denken ist, da dieselben nicht in nachweisbarer Menge in das Bulbusinnere eindringen, ist durch sorgfältige Untersuchungen sicher gestellt [besonders Stuelp ${ }^{1}$ ) und Addario $\left.{ }^{2}\right)$. Man hat dieselben deshalb nach dem Vorschlage Mellinger's vielfach durch Kochsalzinjectionen ersetzt. In solchen Dingen hat jedoch die klinische Erfahrung das letzte Wort zu sprechen, und ich persönlich neige der Ansicht zu, dass bei frischen Entzïndungen die subconjunctivalen Sublimatinjectionen $11: 2000$ in physiologischer Kochsalzlösung) doch noch mehr leisten, als das Kochsalz. Ich verwende daher in der ersten Zeit fast ausschliesslich Sublimatinjectionen, täglich oder jeden zweiten Tag applicirt, und gehe erst mit dem Rückgang der entzündlichen Erscheinungen, oder wenn die Bindehaut zu sehr angegriffen erscheint, za den viel besser vertragenen $2 \%$ Kochsalzeinspritzungen iiber.

Niemals angewendet habe ich Blutentziehungen, hingegen vielfach einen mässigen Gebrauch von der Diaphorese gemacht. Von derselben glaube ich nicht nur eine günstige Einwirkung auf Resorption von Exsudaten, sondern vielfach auch direct auf den entzindlichen Process gesehen zu haben. Besonders die subacuten, fibrinösen Uveitiden mit reichlicherer Exsudation scheinen mir für Schwitzbäder geeignet zu sein - etwa zwei Mal wöchentlich im Heissluftapparat.

Vielleicht am wenigsten befriedigende Resultate hatten wir bis-

7) Archiv f. Atgenheilk. Bd. XXXI. S. 329. 1895.

2) v. Graefe's Arch, f. Ophthalm. Bd. XLVIII. S. 375. 1899. 
Zur Diagnose, Prognose u. Therapie d. perforir., inficirten Augapfelverletzungen. 43

her durch Anwendung der Antiseptica erzielt. Erst in neuester Zeit scheint in dem Jodoform, das schon Ostwalt nach Experimenten an Kaninchen zur intraocularen Desinfection empfohlen hatte, ein Mittel gefunden zu sein, das bei der Bekämpfung eitriger und fibrinöser Uveitiden gute Dienste leistet. Haab ${ }^{1}$ ) and Nayweg ${ }^{2}$ ) empfehlen es warm, wenngleich natuirlich auch sie Misserfolge und sogar sympathische Entzündung gesehen haben.

Durch meine Studien über sympathische Entzündung und die dominirende Rolle, welche das Quecksilber bei ihrer-Behandlung spielt, wurde ich dazu veranlasst, auch bei den infectiösen Uveitiden nach Verletzung, die ich ätiologisch für gleichwerthig halte, ausgedehntere Versuche mit Quecksilber zu machen, und die erzielten Resultate waren so gute, dass ich dem Quecksilber in bohen Dosen den ersten Platz bei der Behandlung inficirter Bulbuswunden einräume, und ich kann mich der Ansicht Haab's, dass man mit Inunctionen meist viel zu spät komme (loc. cit. S. 426), durchaus nicht anschliessen. Daneben lege ich auf längeres Einhalten absoluter Bettruhe grosses Gewicht.

Wenn ich eine inficirte Verletzung in Behandlung bekomme, so frage ich nicht, wie schwer ist dieselbe, wie viel Quecksilber ist wohl nöthig, sie zu bekämpfen, sondern nur, wie viel Quecksilber verträgt der Patient wohl. Denn ich habe mich überzeugt, dass nur hohe, längere Zeit fortgesetzte Dosen gute Resultate geben. Als Applicationsweise habe ich die Inunctionen gewählt, und zwar lasse ich im Allgemeinen bei Männern $8-9 \mathrm{~g}$ pro die, bei Frauen $6-8 \mathrm{~g}$, eine Hälfte Morgens, die andere Abends verreiben, so dass in drei Tagen eine Tour beendet ist; Kinder reiben nach ibrem Alter $1-3 \mathrm{~g}$. Wo jch besonders schnelle Wirkung erzielen will, besonders bei eitrigen Processen, habe ich mit den Inunctionen intramusculäre Einspritzungen von Hydrargyrum bijodatum combinirt ( $\mathrm{Hg}$ bijod. 0, 25 , Kalii jod. ${ }^{3}$ ) 2,5, Aq. dest. 25,0, 1 Pravaz'sche Spritze in die Glutäen), das sehr schnell resorbirt wird, und dessen Eirfluss auf den entzündlichen Process bisweilen schon nach einem halben Tage deutlich wurde. Den subconjunctivalen Sublimatinjectionen schreibe ich, wie oben erwähnt, keine antiseptische, sondern nur lymphtreibende Wirkung zu.

In dieser hohen Dosis liess ich je nach dem Verlauf der Ent-

1) Ueber intraoculare Desinfection. Utrechter internationaler Ophthalm. Congress. S. 42 อ. 1899

2) Ueber intraoculare Desinfection. Heidelberger Ophthalm. Congress. 1900. S. 154.

$\left.{ }^{8}\right)$ Jodkalium ist zur Lüsung des Quecksilberbijodid nothwendig. 
zündung zwei bis vier Touren reiben, um dann auf $5-6 \mathrm{~g}$ und noch später auf $3-4 \mathrm{~g}$ zu fallen. Für die Erzielung guter Resultate ist die längere Application hoher Dosen durchaus erforderlich, und es soll deshalb von vorn herein auf sorgfältigste Mundpflege and kräftige Ernährung das grösste Gewicht gelegt werden. Ich habe in keinem Falle bedenkliche Folgeerscheinungen beobachtet und auch nur ausnahmsweise constatiren könnell, dass die Patienten körperlich sehr herunter kamen.

Diese energische Quecksilberapplication ergab mir ebenso bei fibrinösen, wie bei eitrigen Entzüudungen sehr gute Resultate; vielleicht noch bessere bei den fibrinösen Uveitiden. In allen Fällen, wo ich hier enucleiren nusste, mit Ausnahne eines einzigen, fand sich neben der fibrinösen Entziundung des vorderen Abschnittes eine Eiterung im Glaskörper. Hier hatte ich in der That mitunter den Eindruck, dass das Quecksilber zu spät kommt, und ich habe deshalb in letzter Zeit stets neben den Inunctionen intramusculäre Einspritzungen in den ersten Tagen angewandt. Vielleicht wären hier durch Combination des Quecksilbers mit intraoculärer Jodoformeinführung noch bessere Resultate zu erzielen.

Wie viel aber auch das Quecksilber allein leistet, mag folgender Fall zeigen, wo ausser der Eiterung noch ein Fremdkörper im Bulbus sich fand.

Fall 59. Dem 45jährigen Müller Albert K. flog am 31. XII. 1900 ein Splitter ins linke Auge; das anfangs gute Sehvermögen war am folgenden Tage exheblich herabgesetzt. Am 2. I. 1901 erste Vorstellung. Es fand sich selrr starke gemischte Injection, in der Sklera temporal oben eine kleine Wunde, die Iris stark verwaschen, hyperämisch und verfärbt, reichliches fibrinöses Exsudat in der Vorderkammer und ein Hypopyon, so dass ein Einblick ins Augeninnere unmöglieh ist. Das Sideroskop weist einen Eisensplitter in der Wundgegend nach. - Sofort wird derselbe mit dem grossen Magneten in die Vorderkaminer gezogen und von da mit einem Stück Iris, in das er sich eingekeilt batte, entfernt, sein Gewieht betrug $0,0125 \mathrm{~g}$; zugleich wird das zähe Hypopyon und ein grosser Theil des Pupillarexsudats herausgeholt. Subconjunctivale Sublimatinjection, Hydrargyrum bijodatum in die Glutäen, Inunctionen $8 \mathrm{~g}$ pro die, $4 \%$ Atropinsalbe, feuchter Verband, Bettruhe.

In den folgenden zwei Tagen hatte sich das Pupillarexsudat erneuert, sonst war ansser etwas Chemose keine Veränderung eingetreten; Ciliakoörper etwas schmerzhaft. Die intramusculären und subconjunetivalen Einspritzungen werden täglich wiederholt. Erst am 5. I. beginnt das Pupillarexsudat sieh zu verkleinern, und man sieht jetzt in der Wuadgegend einen ausgedehnten, gelben Glaskörperabseess. Statt Sublimat wird nun täglich Kochsalz unter die Bindehant gespritzt. Die Besserung schrit regelmässig rorwärts, das 
Pupillarexsudat resorbirt sich stetig mehr, und auch der Glaskörper beginnt sich aufzuhellen, der Bulbus blasst ab. Nachdem zwei Touren zu $8 \mathrm{~g}$ gerieben sind, wird die dritte $z u \quad 6$, die vierte $z u 5$ und die weiteren Touren rom 17. I. bis zum 7. II. $z u \quad 4 \mathrm{~g}$ gerieben. Am 14. I. steht Patient zum ersten Mal auf, am 21. T. beginnt die Papille sichtbar zu werden.

Am 8. II. ist das Auge blass und reizlos, aber im Glaskörper noch recht erhebliche Trübungen in der temporalen Hälfte. Visus mit $+1 \mathrm{D}=2 / 3$. Auf seinen dringenden Wunseh wird Patient mit Sublimatpillen entlassen und ihm noch eine Spritze voll Hydrargyrum salicylicum in die Glutäen mitgegeben. - Das Auge hat sich seitdem gut gehalten; bei der letzten Vorstellung am 18. III. 1901 ist das Sehvermögen fast normal und im Glaskörper nur noch in der Wundgegend eine kleine Flocke sichtbar.

Dass in diesem Falle die Heilung so glatt und regelmässig verlief, schreibe ich in erster Linie dem langen Gebrauch höherer Quecksilberdosen zu. Es ist entschieden gefährlich, nach eingetretener Besserung diese Gaben auszusetzen oder auch nur erheblich zu verringern; zu leicht stellt sich dann ein Rückfall der Entzündung ein, welcher zu seiner Heilung meist viel längerer Zeit und viel höherer Quecksilbergaben bedarf. Folgende zwei Fälle sind exquisite Beispiele hierfür:

Fall 10. Die 2jährige Patientin wurde gestern gegen das linke Auge geworfen. Sie kommt am 15. I. 1896 mit leicht gerötheten und geschwollenen Lidern und leblafter Ciliarinjection. Grössere Hornhautwunde mit eitrig infiltrirten Rändern, Iris verfärbt und verwaschen, Kammerwasser getrübt.

Die Wundränder werden mit dem Galvanokauter verschorft, Atropin und Verband gegeben und drei Mal täglich $1 \mathrm{~g}$ Ung. cin. gerieben; Bettruhe. Hierbei geht in den ersten Tagen die Entzündung sehr gut zurück, die Iriszeichnung wird dentlicher, das Kammerwasser klarer, so dass ich am fünften Tage die Inmetionen aussetzte; die übrige Therapie wurde beibehalten.

Drei Tage später war das Auge wieder stärker injicirt, und obgleich die Hornhautwunde sich mehr und mehr reinigte, doch die Iris stärker verschwommen and aufgelockert, der Druck etwas herabgesetzt. Ich liess deshalb wiederum $2 \mathrm{~g}$ Ung. cin. täglich einreiben und diese Inunctionen 14 Tage lindurch regelmässig fortsetzen. Hierbei trat bald ein Umschwung zum Besseren ein; alle entzündlichen Erscheinungen nahmen ab, der intraoculare Druck stellte sich wieder her, die Hornhautwunde vernarbte, und am 12.II. konnte das Kind mit blassem, reizfreiem Auge entlassen werden. Functionsprüfung ist unmöglich, aber gutes rothes Licht zu erhalten.

Fall 50. Dem 22jährigen Arbeiter Ludwig G. sprang am 1. X. 1900 bei einem Feuerwerk ein eiserner Nagel in den rechten Augapfel, den er sich sofort selbst wieder herauszog. In den nächsten Tagen stellten sich leichte Schmerzen ein, und das Sehvermögen nahm stetig ab. Bei der Vorstellung hier am 4. X. fand sich unterhalb der Hornhaut eine rundliche, eitrig belegte Skleralwunde, in der Uvea liegt. Starke ciliare Injection; 
Iris verwaschen und verfärbt, grosses fibrinöses Exsudat in der Forderkammer, Hypopyon, graugelbe flottirende Massen im Glaskörper. Ciliarkörper druckemptindlich. Hg bijod. in die Glutäen, $2 \frac{1}{2}$ Theilstriche Sublimat subconjunctival, $4 \%$ Atropinsalbe, feuchter Verband, Bettruhe.

Am folgenden Tage sind etwas Chemose und Lidödem aufgetreten, aber wohl mehr auf die subconjunetivale Injection zu beziehen. Die gleiehen Injectionen, wie an Tage vorher. - Auch an 6. X. wird die gleiche Therapie angewandt, da die entzündlichen Erscheinungen keine Neigung zur Rückbildung zeigen; das Pupillarexsudat nimmt einen mehr eitrigen Charakter an. - Am 7. X. ist die Druckemptindlichkeit des Ciliarkörpers gesehwunden, und das Vorderkammerexsudat beginnt, sich etwas zusammenzuziehen. Es wird die letzte intramusculäre Einspritzung gemacht und mit Einreibungen, $8 \mathrm{~g}$ pro die, begonnen, ausserdem zwei Mal wöchentlich Schwitzen; die subconjunctivalen Injectionen werden noch bis zum $11 . \mathrm{X}$. fortgesetzt.

Von nun ab schritt die Besserung regelmässig vorwärts und zwar viel schneller im vorteren, als im hinteren Bulbusabschnitt. Am 14. X. ist das Kammerwasser schon ziemlich klar, dabei aber nur nach oben etwas rothes Lieht zu erhalten. Acht Tage später hat sich der Glaskörper schon so weit geklärt, dass man grosse, flottirende Membranen darin unterscheiden kann. Das Auge blasst ab. Patient darf täglich zwei Stunden aufstehen.

Ich fiel jetzt mit den Einreibungen auf $4 \mathrm{~g}$ pro die und setzte dieselben bei fortschreitender Aufhellung des Corpus vitreum am 5. XI. ganz aus, ebenso das Selwitzen, und gab dafür Jodkalium 8:200 und Kochsalzinjectionen. Das Sehvermögen war dabei anf fast $1 / 5$ der Norm gestiegen und die Papille verwaschen zu sehen.

Aber das Quecksilber war zu früh ausgesetzt. Am 12. XI. war der fast völlig blasse Bubus ein wenig injieirt, am 13. XI. noch mehr und das Spiegelbild war etwas trüber geworden; ebenso am 14.XI. und am 15. Xl.; an diesem Tage liessen sich auch mit der binoenlaren Lupe Descemet'sche Beschläge nachweisen. Ich hatte bisher absichtlich die Therapie nicht geändert, um mich zu überzeugen, ob wirklich nach bisher so günstigem Verlauf ein Recidiv anftrete; nun aber war keine Zeit zu verlieren. Der Patient wurde wieder mit $6 \mathrm{~g}$ Ung. cin. täglich eingerieben, das Ange feucht verbunden und absolnte Bettruhe angeordnet. Noch zwei Tage lang wahm die Injcction zu; am 18. XI. zeigt sich sogar ein kleines Hypopyon am Boden der vorderen Kammer; dann aber blasste das Ange wieder ab, und der Glaskörper klärte sich wiederum mehr. Die Inunetionen wurden ietzt auf $4 \mathrm{~g}$ pro die reducirt; hiervon aber waren sieben Touren nöthig, bis die Beschläge vollig verschwunden und das Auge ganz blass und reizfrei geworden war.

Erst am 15. I. konnte Patient mit S. $<1 / 4$ und einem recht gut geklärten Glaskörper, der aber doch noch eine Anzahl flottirender 'Trübungen enthielt, entlassen werden. Er hatte bei der ersten Entzündung 96g, bein Recidiv $186 \mathrm{~g}$ Ung. cin. gerieben - im Ganzen $274 \mathrm{~g}$ im Laufe eines Vierteljahrs - und dieselben ausgezeichnet vertagen. $\mathrm{Zu}$ Hause soll er noch $1 \mathrm{~g}$ Jodkalium täglich nehmen und nicht arbeiten.

Vier Wochen später stellte er sich wieder vor; der Glaskörper ist noch 
Zur Diagnose, Prognose u. Therapie d. perforir., inficirten Augapfelverletzungen. 4 ษ

nicht völlig klar, das Sehvermögen auf $1 / 2$ der Norm gestiegen. - Alles ansgesetzt, Patient darf arbeiten; das Auge ist gut geblieben.

Alle diese durch zu frühes Aussetzen des Quecksilbers entstandenen Recidive erwiesen sich als leidlich gutartig. Es bedurfte jetzt allerdings erhöhter und längere Zeit hindurch fortgesetzter Quecksilbergaben; das Endresultat war aber doch in allen Fällen Heilung. Als viel schwerer erwiesen sich die Rückfälle, die nach zu frithen oder zu schnell nach einander unternommenen Operationen auftraten (z. B. Nr. 11, 12, 36), und ich habe Augen, deren Uveitis schon als geheilt angesehen werden durfte, noch nachträglich durch eine zu früh unternommene, optische Operation verloren. Gerade die Falle von Uveitis fibrinosa haben sich hier als besonders bösartig erwiesen und verrathen auch hierdurch ihre nahe Verwandtschaft mit der sympathischen Entzündung. Für diese ist ja die Gefährlichkeit frihzeitiger operativer Eingriffe seit langem bekannt, und man verlangt im Allgemeinen ein halbjähriges, entzündungsfreies Intervall, ehe zu einer optischen Operation geschritten werden darf. Auch bei der trammatischen Uveitis fibrinosa bin ich dazu gekommen, den Kranken nach vollendeter Heilung mindestens auf ein Vierteljahr nach Hause zu schicken und erst nach dieser Zeit zu operiren; ein jetzt unternommener Eingriff hat sich bisher in allen Fällen als ungefährlich erwiesen.

Folgende zwei Fällen zeigen sehr deutlich das Gefährliche zu frihen Operirens:

1. Nr. 11 der Tabelle. Der 5jährige Albert Th. warle vor acht Tagen mit einer Haselgerte ins linke Auge geschlagen. Bei der Vorstellung: am 2. II. 1896 fand sich das Ange lebhaft pericorneal injicirt; die äussere Hälfte der Hornhaut war durehquert von einer langen, strichförmigen Wunde, deren Ränder mit fibrinös-schleimigen Massen bedeckt sind, und welcher die Iris in grossem Umfange adhärirt. Iris verfärbt und verwaschen, graues Pupillarexsudat; Druck breiweich. - Atropin, Verband, Bettruhe. Kein Quecksilber.

Bei dieser Therapie liess ganz allmählich die Entzündung nach, die Iris gewann ein besseres Aussehen and die Injection versehwand; vom 1 . III. ab blieb das Auge ohne Verband und vertrug es gut. Aber die Synechien hatten sich nicht mehr gelöst, die Pupille war ausserordentlich eng und deshalb volfübrte ich, theils aus optischen Gründen; theils nm einer möglicherweise zu Hanse eintretenden Drucksteigerung vorzubengen, am 7. III. eine breite Iridektomie nach oben innen. Die Operation verlief glatt, das Colobomgebiet erschien klar. Schon am nächsten Tage fanden sich Blntcoagula im Colobom, das Auge erschien stärker injicirt, der Druek etwas vermindert. Bald gesellten sich neue Exsudatmassen hinzu, die das Colobom völlig verlegten, die Iris bekam ein schlechtes Aussehen, der Reizzustand nahm zu, 
der intraoculare Druck verminderte sich stetig, so dass ich mich am 18. III. zur Resectio optico-eiliaris entschliessen musste.

2. Der folgende Fall aus früherer Zeit ist nicht in der Tabelle enthaiten.

Dem 14jährigen Steinmetz Ernst B. Hog am 26. XI. 1894 ein Stïckchen Stein gegen das linke Auge. Als el zwei Stunden später in die Klinik kam, fand sich eine grosse Hornhautwunde, die noch etwas in die Skler'a reicht, ansgedehnter Irisvorfall und traumatische Cataract. - Die Wunde warde sofort gereinigt, die vorgefallene Iris abgetragen, von den Linsenmassen möglichst viel heransgeholt und dicht am Limbus eine Cornealnaht angelegt. Atropin, Verband, Bettruhe.

Im Laufe von vier Wochen heilte die Corneawunde allmählich, erhebliche entzundliche Erscheinungen oder Exsudation traten niemals ein, aber ler Verlauf war doch auch nicht so reactionslos, wie man bei einer aseptischen Wunde hätte erwarten sollen, so dass ich eine ganz leichte Infection annahm. Am 24. XII. wurde Patient mit völlig klarer Iris, aber noch nicht ganz abgeblasstem Auge entlassen. Es wurden Finger auf 3 m gezählt: der Druck war normal.

Am 26. I. 1895 war der Zustand unverändert; immer noch ab und an leichte Injection nad Reizzustảnde. Patient wird zur Discision des Nachstaars aufgenommen, und diese am 28. I. 1895 mit der Nadel ausgeführt. Klaffende schwarze Liicke.

Von diesem Tage ging es abwärts. Die Injection nahm allmählich zu, die Jris verfärbte sich mehr and mehr, die Glaskörperpupille verlegte sieh dureh Exsudat, das sich allmählich in Schwarten umwandelte, der Druck sank, der Ciliakörper wurde druckempfindlich, und das Sehvermögen ging verloren. Am 25. T. 1895 musste ich zur Verhutung sympathiseher Ophthalmie bei ausgesprocliener Phthisis dolorosa die Resectio optico-ciliaris ausführen.

\section{Prognose.}

Die Prognose gestaltet sich bei der auf vorstehenden Seiten skizzirten Behandlung durchaus nicht so schlecht, wie sie nach den eingangs aus der Literatur citirten Aeusserungen zu sein schien. Freilich Statistiken, die man zum Vergleich heranziehen könnte, giebt es nicht, da nirgends bisher die Eintheilung in aseptische und inficirte Verletzungen durchgefuhrt ist. Doch ist nach meinen Erinnerungen iu früherer Zeit auch nicht annähernd ein so grosser Procentsaiz dieser Augen erhalten worden. In der Greifswalder Klinik z. B. sind in den zwei Jahren ror der Quecksilberbehandlung ron neun Augen mit Uveitis fibrinosa acht und von sieben mit Uveitis purulenta sechs verloren gegangen. Das sind allerdings wohl besonders ungtinstige Zahlen.

Stelle ich in derselben Weise, wie früher die aseptischen Verletzungen, jetzt die traumatischen Entzündungen zusammen, so ergiebt sich folgendes Resultat: 
Zur Diagnose, Prognose a. Therapie d. perforir., inficirten Augapfelverletzungen. 49

\begin{tabular}{|c|c|c|c|c|c|c|c|c|}
\hline & $\begin{array}{c}\text { Enucleirt } \\
\text { oder } \\
\text { exenterixt }\end{array}$ & Reseeirt & $\begin{array}{l}\text { Reizioser } \\
\text { blinder } \\
\text { Bulbus }\end{array}$ & $\begin{array}{c}\text { Finger- } \\
\text { zälilen } \\
-\mathrm{S}<1 / 10\end{array}$ & $\begin{array}{l}\text { S. } 1 / 10- \\
\text { s. }<5 / 10\end{array}$ & 8. $510-1$ & $\begin{array}{c}\text { S. } \\
\text { brauchbar, } \\
\text { aber nieht } \\
\text { bestimmbar } \\
\text { (Kinder) }\end{array}$ & Sa. \\
\hline $\left.\begin{array}{c}\text { Uveitis } \\
\text { fibrinosa }\end{array}\right\}$ & 6 & 6 & 4 & 6 & 12 & 2 & 3 & 39 \\
\hline $\left.\begin{array}{c}\text { Ureitis } \\
\text { purulenta }\end{array}\right\}$ & 7 & & & 3 & 3 & 7 & & 20 \\
\hline
\end{tabular}

Es gingen also von 39 Augen mit Uveitis fibrinosa 16 für das Sehen verloren, - hiervon war etwa die Hälfte mit Glaskörperabscess combinirt - während 23 Kranken nicht nur der Augapfel, sondern auch ein geringerer oder grösserer Theil des Sehvermögens erhalten wurde. Von 20 Augen mit Uveitis purulenta gingen 7 verloren, während 13 erhalten wurden. Das macht für die Uveitis fibrinosa $60 \%$ Heilungen, für die Uveitis purulenta $65 \%$ Heilungen. Die drei Fälle von Uveitis serosa wurden sämmtlich geheilt. Besonders möchte ich noch hervorheben, dass ich keinmal das Auftreten sympathischer Entzündung beobachten musste, obgleich doch viele, auch unglïcklich verlaufende Fälle, lange Zeit hindurch conservativ behandelt wurden. $\mathrm{Ob}$ ich dies einem. Zufall zu verdanken habe, oder ob das Quecksilber die Bakterien schwächt und dadurch zur Ueberwanderung weniger geeignet macht, muss dahingestellt bleiben. Jedenfalls zeigte mir die mikroskopische Untersuchung einer Anzahl aus Furcht vor sympathischer Entzündung enucleirter Bulbi, dass die Entzündung in der Aderhaut kaum erst den Aequator bulbi erreicht hatte, also von einer Propagation auf den Opticus noch weit entfernt war. Die Augäpfel waren theils wegen Glaskörperabscess, theils wegen einfacher fibrinöser Uvealentzündung vier Tage bis vier Wochen nach der Verletzung entfernt worden.

Neben der Ausdehnung der mechanischen Veränderungen und der Schwere der Infection ist für die Prognose von besonderer Bedeutung, dass recht frühzeitig mit der Quecksilberbehandlung begomnen wird. Von den acht Fällen von Uveitis fibrinosa, die nach dem vierten Tage in meine Behandlung kamen, konnte nicht ein einziger gerettet werden. Es muss deshalb angestrebt werden, dass solche Verletzungen mit möglichster Beschleunigung einer Augenklinik überwiesen werden; denn natürlich ist eine so energische Behandlung nur in einer Klinik möglich. Jeder verlorene Tag verschlechtert die Prognose. Kommt aber der Verletzte in den ersten

v. Graefe's Archiv für Ophthalmologie. LIII. 1. 
zwei Tagen, damn kann in der Mehrzahl der Fälle Heilung erreicht werden, und ich bin überzeugt, dass sich auch noch bessere Resultate, als wie oben angegeben, mit dieser Behandlungsweise erreichen lassen, wenn man sich erst vollständig mit ihr vertraut gemacht hat. Ein Blick auf die Tabelle lehrt, dass meine Resul. tate in den letzten Jahren entschieden bessere gewesen sind, wie in den ersten, wo ich mir noch nicht im Klaren war, wie hohe Quecksilberdosen nöthig sind und wie lange Zeit hindurch sie gegeben werden müssen.

Die Prognose hängt weiter wesentlich ab von dem Sitz der Verwundung. Infectionen des vorderen Bulbusabschnittes sind stets viel leichter zu bekämpfen, als solche des hinteren Abschnittes, und es ist deshalb von Bedeutung, zu unterscheiden zwischen Tritis, IridoCyclitis und Uveitis. Von besonderer Wichtigkeit ist dies bei der eitrigen Infection, da Weiterkriechen der Eitererreger in den hinteren Bulbusabschnitt und nachträgliche Entwicklung eines GlasIxörperabscesses bei richtiger Therapie zu den Seltenheiten gehört. Man kann daher hier schon nach dem Anfangsbefund die Vorhersage mit grösserer Sicherheit formuliren, wie bei der fibrinösen Entzündung, die grosse Neigung hat, sich weiter auszubreiten. Von wie weittragender Bedeutung die Existenz eines Glaskörperabscesses neben der fibrinösen Iritis oder Irido-Oyclitis ist, habe ich oben mehrfach betont und mich bemüht, die Symptome aufzufinden, die uns eine Frühdiagnose desselben ermöglichen.

Zum Schluss fasse ich die Hauptpunkte dieser Arbeit in einigen Sätzen zusammen:

1. Die infectiöse Entziundung nach perforirenden Bulbusrerletzungen localisirt sich in einem oder mehreren Theilen der Crea oder im Glaskörper.

2. Sie tritt hier in dreifacher Form auf: 1. als Uyeitis serosa, 2. als Uveitis fibrinosa, und 3. als Uveitis purulenta. Beim Glaskörperabscess findet man anatomisch Hyperaemie und Infiltration in Notz- und Aderhaut; in ersterer häufig mehr, als in letzterer.

3. Die drei Uveitisformen sind nicht scharf ron einander geschieden, sondern gehen in einander über oder existiren neben einander im gleichen Auge; speciell ist die klinisch als Uveitis tibrinosa erscheinende Entzündung nicht selten mit Eiterung im Glaskörper combinirt.

4. Diese Combination, welche die Prognose sebr verschlechtert, ist bei Undurchsichtigkeit der brechenden Medien zu vermuthen, wenn 
Zur Diagnose, Prognose u. Therapie d. perforir,, inficirten Augapfelverletzungen. 51 bei einer bis in den Glaskörper reichenden Verwundung reichliches Vorderkammerexsudat und Druckempfindlichkeit des Ciliarkörpers innerhalb weniger Tage sich ausbildet.

5. Die Prognose ist bei Uveitis serosa eine gute, bei der Uveitis fibrinosa und Uveitis purulenta eine leidlich gute; es gelingt durch Einverleibung hoher Quecksilberdosen bei beiden Erkrankungen, fast zwei Drittel der Augen mit grösserem oder geringerem Sehvermögen zu erhalten.

6. Operative Eingriffe sollten stets auf längere Zeit hinausgeschoben werden, da sonst leicht Recidive eintreten. Zumal bei der Uveitis fibrinosa sollte man stets ein Vierteljahr nach Ablauf der Entzündung warten, ehe man operirt.

Anmerkung. Zur Zeit stehen wieder zwei Glaskörperabscesse in meiner Behandlung. Das eine Auge, nach 30 Stunden kauterisirt und der geschilderten Behandlung unterworfen, wird mit grösster Wahrscheinlichkeit durchkommen; das andere, das erst nach neun Tagen in meine Behandlung trat, wird resecirt werden müssen. 